\title{
Regulated recruitment of HP1 to a euchromatic gene induces mitotically heritable, epigenetic gene silencing: a mammalian cell culture model of gene variegation
}

\author{
Kasirajan Ayyanathan, Mark S. Lechner, ${ }^{1}$ Peter Bell, Gerd G. Maul, David C. Schultz, ${ }^{2}$ \\ Yoshihiko Yamada, ${ }^{3}$ Kazuhiro Tanaka, ${ }^{3}$ Kiyoyuki Torigoe, ${ }^{3}$ and Frank J. Rauscher III $^{4}$ \\ The Wistar Institute, Philadelphia, Pennsylvania 19104-4268, USA
}

\begin{abstract}
Heterochromatin protein 1 (HP1) is a key component of constitutive heterochromatin in Drosophila and is required for stable epigenetic gene silencing classically observed as position effect variegation. Less is known of the family of mammalian HP1 proteins, which may be euchromatic, targeted to expressed loci by repressor-corepressor complexes, and retained there by Lys 9-methylated histone H3 (H3-MeK9). To characterize the physical properties of euchromatic loci bound by HP1, we developed a strategy for regulated recruitment of HP1 to an expressed transgene in mammalian cells by using a synthetic, hormone-regulated KRAB repression domain. We show that its obligate corepressor, KAP1, can coordinate all the machinery required for stable gene silencing. In the presence of hormone, the transgene is rapidly silenced, spatially recruited to HP1-rich nuclear regions, assumes a compact chromatin structure, and is physically associated with KAP1, HP1, and the H3 Lys 9-specific methyltransferase, SETDB1, over a highly localized region centered around the promoter. Remarkably, silencing established by a short pulse of hormone is stably maintained for $>50$ population doublings in the absence of hormone in clonal-cell populations, and the silent transgenes in these clones show promoter hypermethylation. Thus, like variegation in Drosophila, recruitment of mammalian HP1 to a euchromatic promoter can establish a silenced state that is epigenetically heritable.
\end{abstract}

[Keywords: KRAB domain; KAP1; HP1; heterochromatin; gene silencing; position effect variegation]

Received April 10, 2003; revised version accepted May 29, 2003.

A recently emerging paradigm for the epigenetic control and propagation of gene expression states involves the role of chromatin structure. Though historically viewed as a passive packaging structure primarily used to assemble the enormous amount of DNA into a eukaryotic nucleus, the nucleosome with its complement of core histones has emerged as a key target for regulating gene expression (Wolffe and Hansen 2001). The dynamic regulation of chromatin organization appears to be accomplished by macromolecular protein complexes that contain enzymatic activities that modify the tails of the core

Present addresses: ${ }^{1}$ Department of Bioscience and Biotechnology, Drexel University, Philadelphia, PA 19104, USA; ${ }^{2}$ Department of Pharmacology, Case Western Reserve University, Cleveland, OH 44106-4965, USA; ${ }^{3}$ National Institute of Dental \& Craniofacial Research, National Institutes of Health, Bethesda, MD 20892-4370.

${ }^{4}$ Corresponding author.

E-MAIL rauscher@wistar.upenn.edu; FAX (215) 898-3929.

Article published online ahead of print. Article and publication date are at http://www.genesdev.org/cgi/doi/10.1101/gad.1102803. histones. The constellation of these histone modifications, including acetylation, phosphorylation, ubiquitination, and methylation, create both synergistic and antagonistic signals that correlate with the transcriptional activity of a gene (Wu and Grunstein 2000). This emerging "histone code" is hypothesized to create functionally distinct subdomains in chromatin that define active versus transcriptionally silent genes (Jenuwein and Allis 2001). Histone modifications and the chromatin-associated proteins that interpret these signals may represent an epigenetic marking system responsible for setting and maintaining heritable programs of gene expression during development.

The role of histone acetylation/deacetylation [mediated by histone acetyltransferases (HATs) and histone deacetylases (HDACs), respectively] in modulating gene activity is now well established (Kuo and Allis 1998). The role of histone methylation in the regulation of chromatin structure and gene transcription has been greatly facilitated by the recent identification of histone 
methyltransferase (HMTase) enzymes (Zhang and Reinberg 2001). The discovery that the mammalian homologs of the Drosophila melanogaster heterochromatin protein $\mathrm{Su}(\mathrm{var}) 3-9$ are H3-specific methyltransferases significantly supported the involvement of histone methylation in gene regulation (Rea et al. 2000). Further, the methylation was highly selective for Lys 9 with the methyltransferase function mapping to the evolutionarily conserved SET (SuVar3-9, Enhancer of Zeste, Trithorax) domain (Rea et al. 2000). Because histone H3, Lys 9 methylation (MeK9) is highly enriched in heterochromatin and other transcriptionally silent regions of the nucleus, it is postulated that this modification might be a vital component of the histone code that controls gene silencing.

The recent discovery that the Lys 9-methylated histone H3 (H3-MeK9) mark establishes a high affinity binding site for the heterochromatin protein 1 (HP1) family of heterochromatin proteins has provided one of the first links between a histone mark and establishment of a repressive chromatin environment for gene expression (Bannister et al. 2001; Lachner et al. 2001; Nakayama et al. 2001). The HP1 proteins are small nonhistone chromosomal proteins that are composed of an $\mathrm{NH}_{2}$-terminal chromodomain (CD), a $\mathrm{COOH}$-terminal chromoshadow domain $(\mathrm{CSD})$, and a variable hinge region that separates these two domains (Wallrath 1998). The CD binds directly, with high affinity to the MeK9 residue in the histone $\mathrm{H} 3$ tail (Bannister et al. 2001; Lachner et al. 2001). The CSD is a homodimerization domain that directly recognizes a consensus pentapeptide sequence, PxVxL with high affinity, which is present in a growing number of nuclear proteins that may target the HP1 protein to specific genes or subnuclear compartments (Lechner et al. 2000; Smothers and Henikoff 2001).

Clues to the biological consequences of HP1-chromatin interaction have come from the study of $D$. melanogaster HP1 (Wallrath 1998). HP1 is intimately involved in the phenomenon of position effect variegation (PEV) in D. melanogaster. Classic PEV is observed when a transcribed euchromatic gene becomes integrated adjacent to a block of silent heterochromatin (Baker 1968; Wakimoto 1998). Transcription is silenced in only a subset of cells, and this state is stably inherited by their progeny thus leading to variegated or mosaic patterns of expression in the adult organism. The stochastic nature of PEV is hypothesized to be due to the variable spreading of heterochromatin (and thus transcriptional silencing) into adjacent regions of the genome (Locke et al. 1988). Genetic screens for modifiers of PEV led to the discovery of the suppressor allele Su(var)2-5 that encoded HP1, a discovery consistent with its earlier identification as a heterochromatin-associated protein in polytene nuclei (James and Elgin 1986). Genetic experiments revealed that HP1 is a strong, dose-dependent modifier of PEV (Locke et al. 1988; Eissenberg et al. 1992). The HP1 protein is physically associated with both constitutive heterochromatin and adjacent variegating transgene, and likely contributes directly to the formation or stabiliza- tion of silent heterochromatin (Eissenberg et al. 1992). As would be expected, these large blocks of HP1-containing heterochromatin are highly enriched in $\mathrm{H} 3-\mathrm{MeK} 9$ (Nakayama et al. 2001). Thus, the discovery of the H3MeK9-HP1 connection establishes a direct link between histone methylation and the stable epigenetic gene silencing, which occurs in or adjacent to large blocks of constitutive heterochromatin.

The above observations prompt two important questions: (1) Can HP1 also participate in the silencing of constitutively expressed euchromatic genes, that is, genes that are not physically adjacent to a large block of silent heterochromatin, and if so, are those silenced states stably heritable? (2) How are the required processes of histone deacetylation, H3-MeK9 methylation, HP1 deposition, and chromatin compaction coordinated in the nucleus? In our previous work, we have approached the latter question by characterizing the KAP1 corepressor. KAP1 displays the hallmarks of a scaffold protein that can recruit and coordinate many of the components required for HP1-mediated gene silencing to specific loci. KAP1 coordinates histone deacetylation via the recruitment of the NuRD complex (Schultz et al. 2001); histone H3 Lys 9 methylation via the action of a novel KAP1-associated histone methyltransferase named SETDB1 (Schultz et al. 2002); and direct binding and deposition of HP1 mediated by a highly conserved PxVxL motif present in KAP1 (Lechner et al. 2000) that interacts with the chromoshadow domain of HP1. Moreover, KAP1 functions as a corepressor by binding directly to the highly conserved $\mathrm{KRAB}$ repression domain that is present in more than 220 human zinc finger proteins, suggesting that this mechanism is likely targeted to a large number of specific loci in vivo (Peng et al. 2000; Abrink et al. 2001).

In the work presented here, we have utilized the KRAB-KAP1 system to answer the first question posed above, that is, can HP1 participate in the silencing of euchromatic genes? Toward this objective, we have created a hormone inducible system in a mammalian cell line that allows transient and reversible targeting of endogenous KAP1 and its associated activities to a highly transcribed euchromatic reporter transgene. We conclude that KAP1 coordinates the establishment of highly localized heterochromatin-like silenced states at euchromatic genes and that these states are epigenetically heritable.

\section{Results}

\section{Hormone regulatable chimeric repressor proteins}

We used a two-plasmid system composed of a regulatable chimeric repressor (Fig. 1A) and a synthetic reporter gene (Fig. 2A). The 90 amino-acid KRAB domain of Kox1 is sufficient to bind KAP1 and is a very strong, DNAbinding-dependent repressor in vivo (Margolin et al. 1994; Friedman et al. 1996). This domain [and a mutant, $\mathrm{KRAB}\left(\mathrm{DV}_{18,19} \mathrm{AA}\right)$, which lacks repression activity and fails to bind KAP1] was fused to the $\mathrm{NH}_{2}$ terminus of the 
A Chimeric repressor proteins:
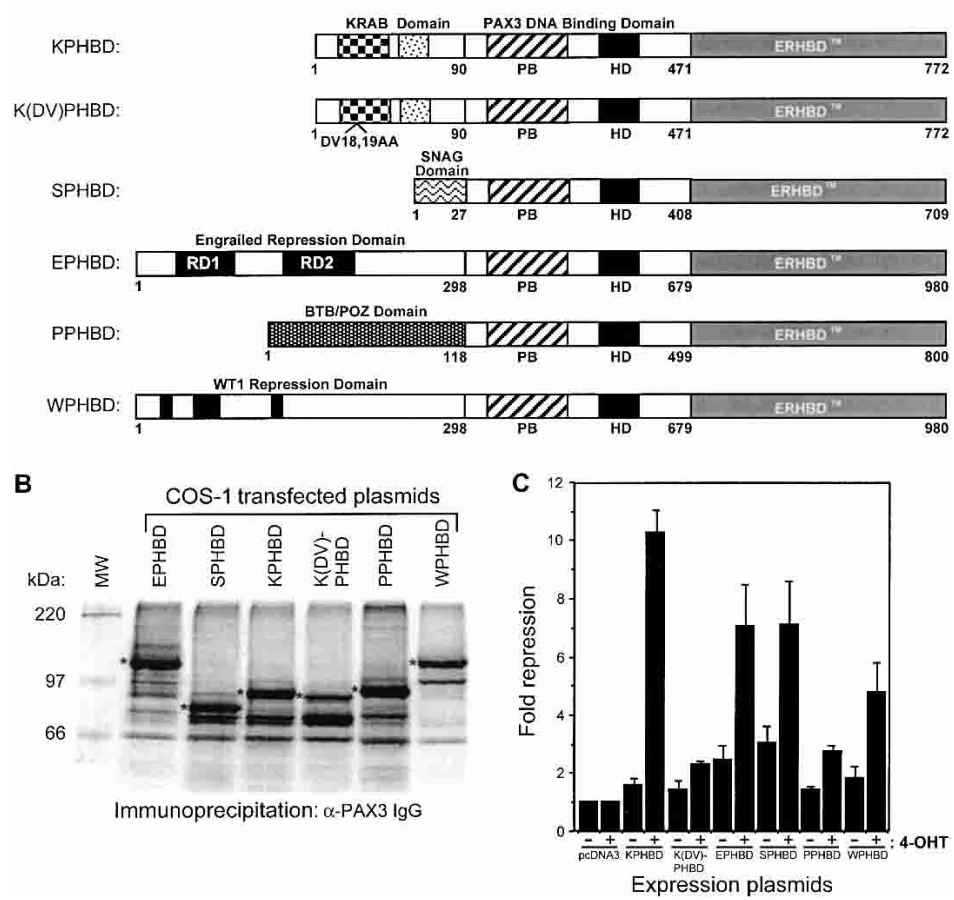

Figure 1. Characterization of chimeric transcriptional repressors. (A) Schematic illustration of repressor proteins. The KRAB, KRAB(DV), SNAG, Engrailed, BTB/ $\mathrm{POZ}$, and WT1 repression domains (RDs) were fused in frame with PAX3-HBD to generate the RD-PAX3-HBD fusion proteins. (B) Immunoprecipitation of transfected cell extracts with $\alpha$-PAX3 IgG. Asterisks indicate the expressed proteins. MW, molecular weight markers. $(C)$ 4-OHT-dependent repression of PAX3-luciferase reporter gene by the chimeric repressors. NIH3T3 cells were transfected with the indicated expression plasmids and the CD19-TK-LUC reporter plasmid. Posttransfection and 4-OHT treatment, cell lysates were assayed for luciferase and $\beta$-galactosidase activities. Fold repression represents the ratio of normalized luciferase activity of $-/+\mathrm{OHT}$ treated cells.
PAX3 DNA binding domain (DBD). To make this chimeric repressor hormone regulatable, we fused the estrogen receptor hormone-binding domain to the $\mathrm{COOH}$ terminus of the PAX3 DBD. The ERHBD contains $\mathrm{G}_{525} \mathrm{R}$ substitution, which renders it unresponsive to serum estrogens (Littlewood et al. 1995). These chimeras are inactive for DNA binding in the absence of hormone. For comparison purposes, we also created artificial repressors using the repression domains (RD) from WT1 (Madden et al. 1991), PLZF-BTB/POZ (Li et al. 1997), Engrailed (Jaynes and O'Farrell 1991), and GFI-SNAG (Zweidler-Mckay et al. 1996; Ayyanathan et al. 2000). Each RD-PAX3-HBD fusion protein was stably expressed in cells (Fig. 1B) and bound the PAX3 recognition sequence (data not shown). However, only the KRABPAX3-HBD protein could form a ternary complex with the KAP1 corepressor and the HP1 protein (data not shown). Thus, this set of chimeric repressors allows a comparison of HP1-mediated and HP1-independent mechanisms of gene silencing.

\section{4-OHT-dependent repression of a transient luciferase reporter template}

The CD19-TK-LUC-Zeo ${ }^{\mathrm{R}}$ reporter plasmid contains six high-affinity PAX3 recognition motifs upstream of the herpes simplex virus (HSV) thymidine kinase (TK) promoter. A zeocin ${ }^{\mathrm{R}}$ gene expressed from an SV40 promoter was incorporated to provide both a selection marker allowing generation of stable cell clones and a second transcription unit linked to the luciferase gene (Ayyanathan et al. 2000). The CD19-TK-LUC-Zeo ${ }^{\mathrm{R}}$ plasmid showed a high basal level of luciferase activity. We observed
4-OHT dependent repression of the luciferase reporter (Fig. 1C) by each RD-PAX3-HBD plasmids. The KPHBD protein was the most potent repressor (>10-fold), while the SPHBD, EPHBD, PPHBD, and WPHBD expression constructs elicited moderate levels of repression $(\sim 3-$ to 6 -fold). The K(DV)PHBD protein was inactive for repression activity, and none of the RD-PAX3-HBD proteins repressed a TK-LUC-Zeo ${ }^{\mathrm{R}}$ reporter, which lacked PAX3 binding sites (data not shown). We conclude that this two-plasmid system comprises a valid, hormone- and DNA-binding-dependent repression model.

\section{4-OHT-dependent repression of chromatinized reporter transgenes}

To create mammalian cell lines with integrated luciferase reporter transgenes, the DNAs for the CD19-TKLUC-Zeo ${ }^{\mathrm{R}}$ luciferase reporter and each of the RDPAX3-HBD fusions were cotransfected into murine NIH3T3 fibroblasts (Fig. 2A). Following selection, clones were expanded, tested for basal luciferase activity, and then tested for 4-OHT-dependent repression activity. As controls, we also generated stable cell lines that contain only the chromatin-integrated luciferase reporter (designated as "CL" clones). At least 48 independent clonal cell lines both for CL and for each RD-PAX3-HBD fusion were tested. A representative selection of five clones for each transfection is shown in Figure 2B and C. The basal normalized luciferase activities, among clones, varied from $\sim 10^{3}$ to $10^{6}$ light units/1 O.D. at $\mathrm{A}_{595}$ protein (Fig. 2B).

The CL clones, which do not contain a stable RDPAX3-HBD gene, showed no response to 4-OHT. How- 
Ayyanathan et al.

A

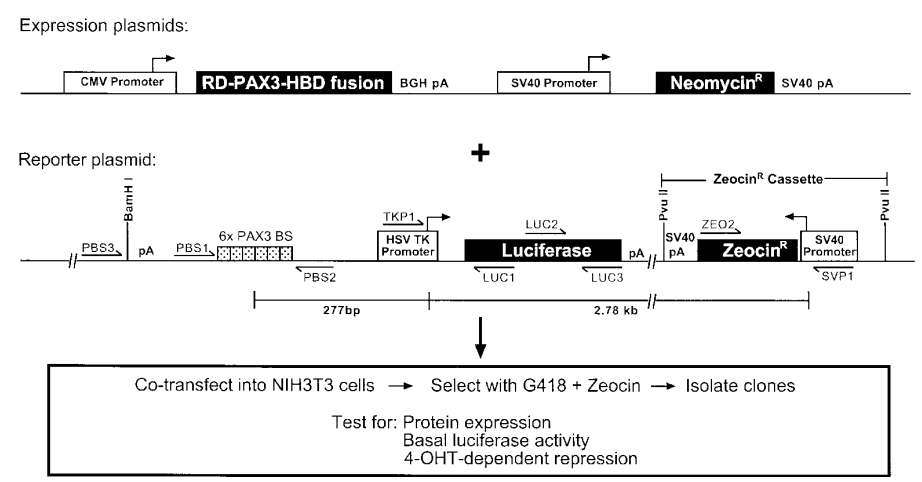

D
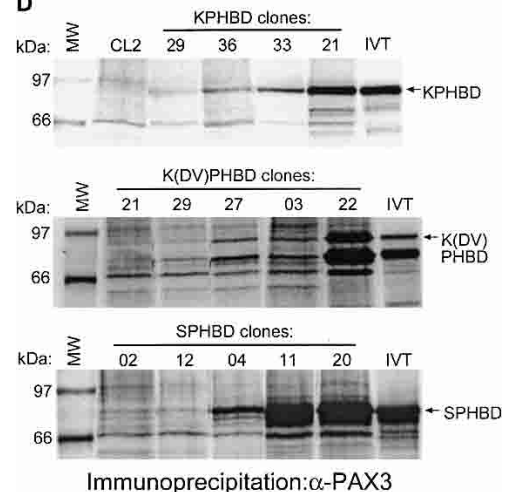

E

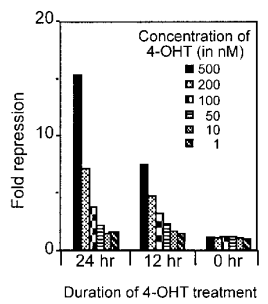

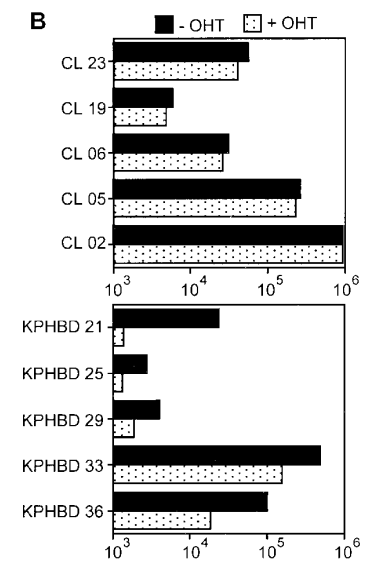

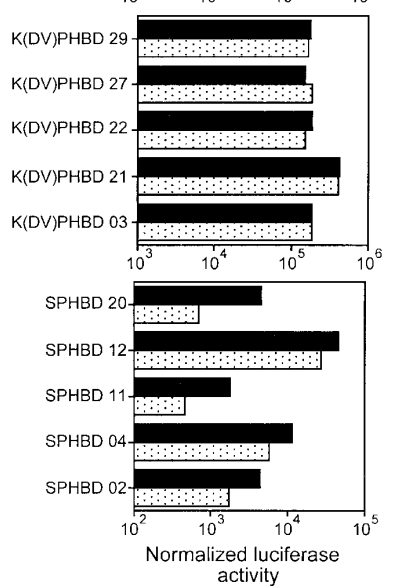

C
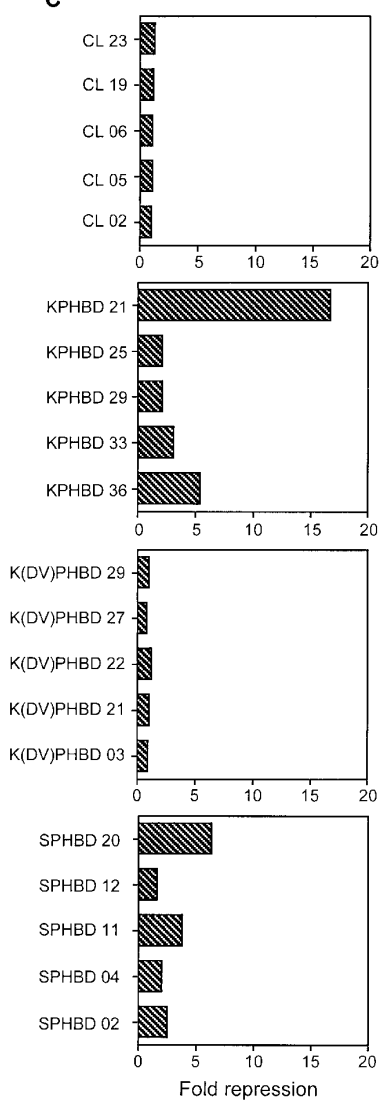

$\mathbf{F}$
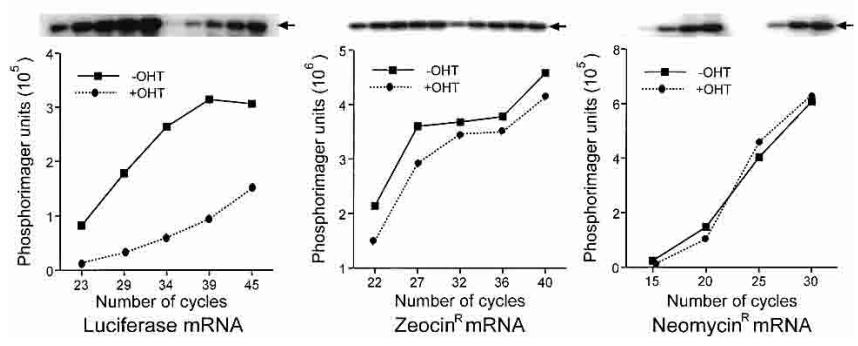

Figure 2. Characterization of stable cell lines. $(A)$ Strategy to generate cell lines. $(B, C)$ 4-OHT-dependent repression of chromatinized PAX3-luciferase reporter gene in stable cell lines. First (top) graphs represent the normalized luciferase activity $(B)$ and fold repression $(C)$ of five independent "CL" (luciferase reporter) clones. Second, third, and fourth graphs illustrate the normalized luciferase activity $(B)$ and fold repression $(C)$ in clones stably expressing the respective RD-PAX3-HBD proteins. $(D)$ Chimeric repressor protein expression in stable cell lines. Gels illustrate the protein expression in KPHBD (top), K(DV)PHBD (middle), and SPHBD (bottom) stable cell lines. Expression of full-length protein is indicated by in vitro-translated protein (IVT). (E, F) Characterization of the KPHBD21 cell line. (E) Time- and 4-OHT-concentration-dependent repression. KPHBD21 cells were treated with vehicle or varying concentrations of 4-OHT for either 0,12 , or $24 \mathrm{~h}$. Fold repression of luciferase activity was determined as above. $(F)$ 4-OHT-dependent transcriptional repression of luciferase gene. Oligo-dT primed first strand cDNAs from vehicle or 4-OHT-treated KPHBD21 cells were monitored for luciferase, neomycin ${ }^{\mathrm{R}}$, and $z$ eocin ${ }^{\mathrm{R}}$ transcripts by quantitative PCR. Arbitrary PhosphorImager units obtained from the Southern analysis are plotted. $\mathbf{\square},-\mathrm{OHT} ; \boldsymbol{\bullet},+\mathrm{OHT}$.

ever, strong 4-OHT-dependent repression was observed in KPHBD21 cell line $(\sim 16$-fold $)$ while the KPHBD30, KPHBD33, and KPHBD36 clones manifested moderate repression activity $(\sim 3$ - to 5 -fold). In contrast, each of the
K(DV)PHBD transfected clones possessed a high basal luciferase activity that was unaffected by 4-OHT treatment. The SPHBD transfection produced clones that showed six- to sevenfold repression in response to 
4-OHT (Fig. 2C). Using metabolic labeling and immunoprecipitation with $\alpha$-PAX3 IgG, each clone expressed full-length RD-PAX3-HBD protein to a level, which correlated roughly with the $4-\mathrm{OHT}$-dependent repression potential of these cells (Fig. 2D). Stable cell lines containing an integrated luciferase reporter and the engrailed-PAX3-HBD (EPHBD), PLZF-POZ-PAX3-HBD (PPHBD), or WT1-PAX3-HBD (WPHBD) were also generated, which showed demonstrable levels of 4-OHT-dependent repression (data not shown). We conclude the following: (1) 4-OHT treatment does not affect the basal expression of the reporter luciferase transgene when stably integrated at many different sites in the genome; (2) the KPHBD protein is a powerful, hormone-dependent repressor of the integrated reporter transgene; and (3) NIH3T3 cells contain the machinery required to support SNAG domain mediated repression.

\section{Molecular characterization of a KRAB-PAX3-HBD stable cell line}

The KPHBD21 clone was further characterized. First, a PCR using genomic DNA showed that the PAX3 binding sites, the TK promoter, the luciferase gene, and the zeo$\operatorname{cin}^{\mathrm{R}}$ cassette were physically linked in the integration site (data not shown). Second, Southern blotting suggested that an estimated two to five copies of the CD19-TK-LUC-Zeo ${ }^{\mathrm{R}}$ were present (data not shown). Third, micrococcal nuclease digestion showed that a compact nucleosome pattern accompanied repression (data not shown). Fourth, repression was strongly time- and 4-OHT-concentration-dependent (Fig. 2E). Fifth, 4-OHT-dependent repression occurred at the level of transcription as shown by decreases in the abundance of luciferase mRNA measured by quantitative reverse transcriptase PCR (RT-PCR; Fig. 2F). However, transcription at both the linked zeocin ${ }^{\mathrm{R}}$ locus and the unlinked neomycin ${ }^{\mathrm{R}}$ locus were unaffected by 4-OHT treatment (Fig. 2F). Thus, KRAB-mediated repression is highly localized, as a linked transcription unit $\left(\right.$ zeocin $^{\mathrm{R}}$ cassette) $\sim 2.8 \mathrm{kbp}$ away from the repressor binding site is unaffected.

\section{KRAB-PAX3-HBD protein induces a highly localized compact chromatin structure}

To begin to dissect the changes in chromatin structure that accompany silencing, nuclease accessibility assays were performed using known restriction enzyme sites in the CD19-TK-LUC-Zeo ${ }^{\mathrm{R}}$ plasmid. As shown in Figure $3 \mathrm{~A}$, each enzyme showed dramatic inhibition of cleavage in the nuclei derived from 4-OHT-treated nuclei. A region of 257 bp flanking the TK promoter and transcription initiation site in the luciferase gene is converted to a compact, nuclease-resistant structure upon 4-OHT treatment. Strong cleavage was observed at both the NcoI and StuI sites in the presence of 4-OHT at the unlinked neomycin ${ }^{\mathrm{R}}$ gene (Fig. 3B). Similar sites in the linked SV40 promoter-zeocin ${ }^{\mathrm{R}}$ gene also showed equal accessibility regardless of 4-OHT treatment (Fig. 3C). Thus, the compact chromatin structure induced by KPHBD binding to the PAX3 sites near the TK promoter is not established at a promoter $2.8 \mathrm{kbp}$ distant.

\section{Recruitment of KAP1 and HP1 to the reporter luciferase transgene}

We performed comprehensive chromatin immunoprecipitation (ChIP) analyses of the integrated locus and the

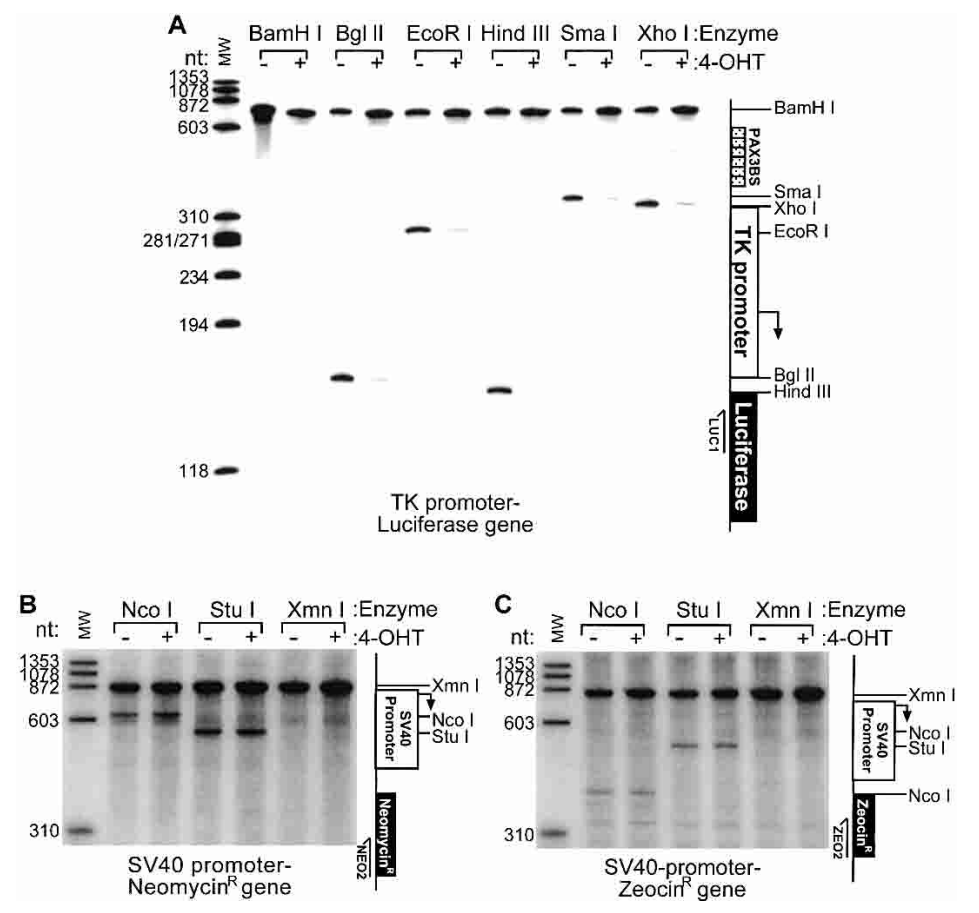

Figure 3. Differential endonuclease accessibility observed only at the luciferase locus. $(A)$ Restriction endonuclease sensitivity at the TK promoter-luciferase locus. Nuclei isolated from vehicle- $(-\mathrm{OHT})$ or $4-\mathrm{OHT}$ (+OHT)-treated KPHBD21 cells were treated with the indicated restriction endonucleases. Purified DNA was used in reiterative primer-extension PCR with LUC1 primer. The denatured products were resolved on UreaPAGE and autoradiographed. $(B, C)$ Restriction endonuclease sensitivity at the neomycin ${ }^{\mathrm{R}}(B)$ and $\operatorname{zeocin}^{\mathrm{R}}$ $(C)$ loci monitored by using NEO2 and ZEO2 primers. MW, radiolabeled $\phi X 174$ HaeIII digest; nt, nucleotide length; PAX3BS, PAX3-binding site. 
results are presented in Figure 4. Using antibodies specific to the PAX3, KAP1, HP1 $\alpha$ and $\mathrm{HP} 1 \gamma$ proteins, the DNA recovered was analyzed by quantitative PCR using primer pairs for regions of the CD19-TK-LUC, zeocin loci (Fig. 2A). Fragments, which bracket the PAX3 binding sites, were strongly enriched (5-10-fold) in the PAX3 immunoprecipitates (IPs) after 4-OHT-treatment. Other components of the $\mathrm{KRAB}$ repression complex (i.e., KAP1, $\mathrm{HP} 1 \alpha, \mathrm{HP} 1 \gamma$ ) were inducibly recruited to the target gene. This enrichment was most evident for the primer pair that directly flanks the PAX3 binding sites (PBS1 and PBS2). This fragment is enriched 10-, 11-, and $~ 5$-fold in PAX3, KAP1, and HP1 $\alpha$ IPs, respectively. No signal (NS) was detected from the CL2 reporter cell line, which lacks a KPHBD repressor expression. The 257 bp fragment spanning the TK promoter and transcription initiation site is most highly enriched in KAP1 and HP1 $\alpha$ IPs, 10and 27-fold, respectively. This is different from HP1 $\gamma$, which is constitutively bound to that region and not enriched upon 4-OHT-treatment. No signal was obtained for the $3^{\prime}$ end of the luciferase-coding region (located 1.2 kbp downstream from the TK promoter; primers LUC2 and LUC3), the SV40-zeocin ${ }^{\mathrm{R}}$ cassette, or the unlinked SV40-neomycin ${ }^{\mathrm{R}}$ cassette (data not shown). Thus, recruitment of KAP1 and HP1 $\alpha$ is highly specific for a target gene regulated by a DNA-bound KRAB repression domain. Moreover, the association of KAP1 and HP1 $\alpha$ to the chromatin occurs in a highly localized region.

\section{Recruitment of KAP1 and HP1 to an endogenous target gene}

To determine whether similar physical characteristics occur at an endogenous target gene that is silenced by a naturally occurring KRAB zinc finger protein, we studied the NT2 KRAB-ZFP (Fig. 5A). NT2 protein is abundant in NIH3T3 cells (Fig. 5B), binds to a 24-bp consensus sequence in the Col11a2 promoter, and silences it (Tanaka et al. 2002; Fig. 5C). NT2 is highly transcribed while the Col11a2 transcript is undetectable suggesting that NT2 is contributing to Coll1a2 silencing in NIH3T3 cells. However, the tightly linked $R X R \beta$ gene, which is present $5^{\prime}$ of Col11a2 is highly expressed suggesting that NT2 mediated silencing is not long range (Fig. 5C,D). Moreover, ChIP experiments demonstrated NT2 at the predicted binding site but not enriched in the proximal promoter region. However KAP1, HP1 $\alpha, \mathrm{HP} 1 \gamma$, and SETDB1 proteins were abundantly present at both regions. The promoter region was also highly enriched in H3-MeK9 (Fig. 5E). These results were strikingly similar to those observed with the integrated transgene and strongly suggest that a localized heterochromatin structure is generated at an endogenous locus silenced by a $\mathrm{KRAB}-\mathrm{ZFP}$.

\section{Spatial relocalization of the luciferase transgene to condensed chromatin}

We performed fluorescence in situ hybridization (FISH) analysis on the KPHBD21 cell line using a probe for the CD19-TK-LUC luciferase reporter plasmid, and the cells were counter-stained with either DAPI or Hoechst dyes to identify condensed heterochromatin structures (Fig. 6A,B). A single locus was observed in the KPHBD21 line in every cell examined, strongly suggesting a single integration site for the reporter plasmid (data not shown). In the absence of 4-OHT, the FISH signals were most frequently found to be spatially distinct from the
Figure 4. KRAB-box-dependent recruitment of KAP1 and HP1 proteins to the integrated luciferase transgene. CL2 and KPHBD21 cells were treated with either vehicle $(-\mathrm{OHT})$ or $4-\mathrm{OHT}(+\mathrm{OHT})$, and the DNA-protein complexes were chemically cross-linked in vivo with formaldehyde. Soluble, sonicated chromatin was immunoprecipitated with $\alpha$-PAX3, $\alpha$-KAP1, $\alpha-\mathrm{HP} 1 \alpha$, and $\alpha-\mathrm{HP} 1 \gamma$ antibodies. Quantitative PCR was carried out with input and immunoprecipitated DNAs using specific primer pairs indicated in Figure 2A. PCR-amplified DNA fragments are depicted from ChIPs with $\alpha$-PAX3, $\alpha-\mathrm{KAP} 1, \alpha-\mathrm{HP} 1 \alpha$, and $\alpha-\mathrm{HP} 1 \gamma$ IgG. Bold vertical lines on the right indicate the relative positions of the transgene fragments amplified. The numbers in parentheses indicate fold enrichment, and NS denotes no signal.

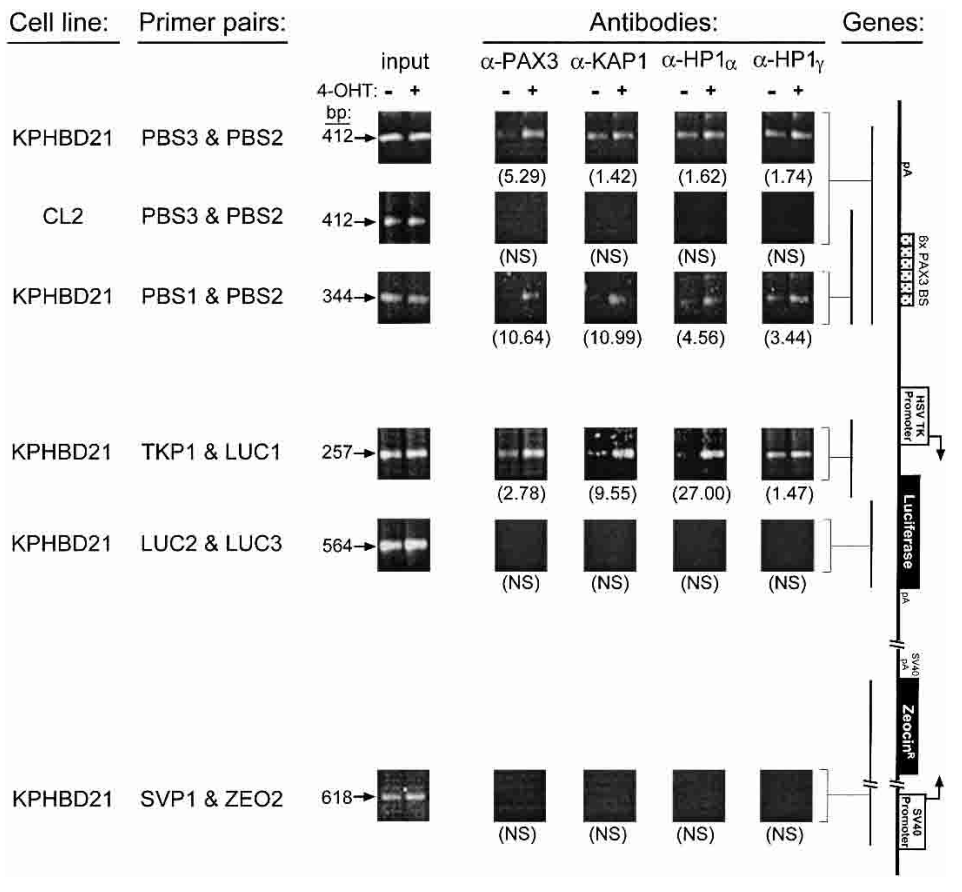




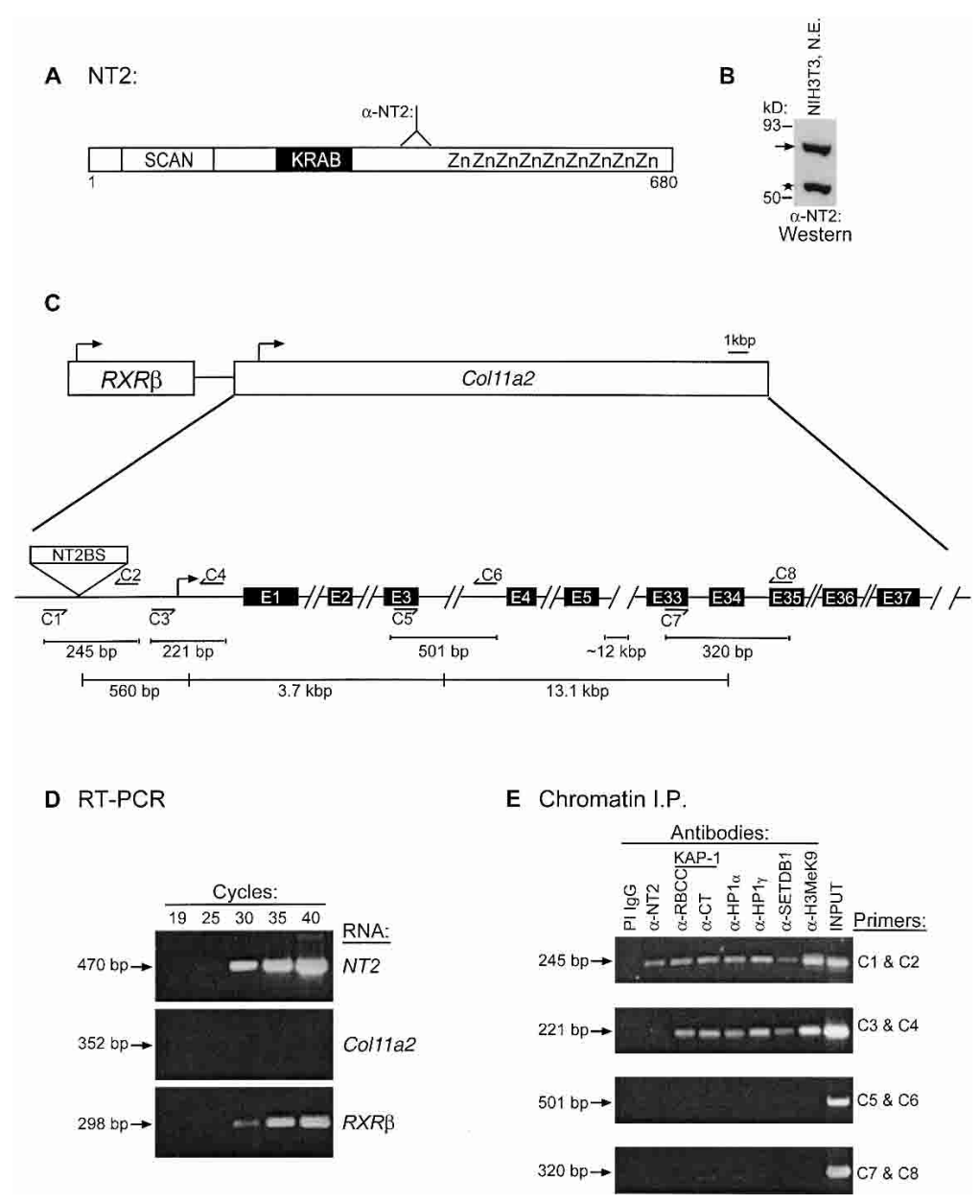

Figure 5. NT2-KRAB zinc finger protein stably represses the expression of endogenous Col11a2 gene in NIH3T3 cells. (A) Diagrammatic representation of the mouse NT2-KRAB zinc finger protein. The positions of SCAN, KRAB domains, ZF motifs, and the antigen used for $\alpha-\mathrm{NT} 2$ antibody production are indicated. $(B)$ Abundant expression of NT2 protein in NIH3T3 cells. Nuclear proteins $(100 \mu \mathrm{g})$ were electrophoresed on a $10 \%$ SDS-PAGE and immunoblotted with affinity-purified $\alpha$-NT2 antibody. The $\sim 75 \mathrm{kD}$ NT2 protein is indicated by an arrow and a nonspecific band is marked by an asterisk. $(C) \mathrm{Ge}$ nomic structure of $R X R \beta$ and Col11a2 genes. The Col11a2 gene is organized in a head-to-tail orientation with $R X R \beta$. The relative locations of oligonucleotides used in ChIP-PCR experiments and the fragment sizes are indicated. E1 to E37 represent the exons of Col11a2 gene. (D) Expression patterns of NT2, Col11a2, and $R X R \beta$ transcripts in NIH3T3 cells. Oligo-dT-primed first-strand cDNAs were amplified by quantitative PCR using primer pairs specific for the NT2, Col11a2, and RXR $\beta$ transcripts and electrophoresed on $1.5 \%$ agarose gel. (E) Components of KRAB repression machinery are enriched at the silenced Col11a2 locus. Cross-linked chromatin was immunoprecipitated with the indicated antibodies and the bound DNA was analyzed by PCR using primers indicated in $C$. condensed chromatin islands as single green dots. However, following addition of 4-OHT, there was a clear association of the majority of luciferase FISH signals with the condensed chromatin territories. We quantitated this pattern by analyzing many cells (Fig. 6C). Using HP1 $\alpha$ antibodies, which stained the heterochromatic islands detected by the DNA dyes, 4-OHT-dependent spatial recruitment of the luciferase FISH signals to the HP1-rich regions was also observed (data not shown). Thus, spatial relocalization of the reporter gene appears to accompany KRAB-KAP1-HP1-dependent silencing in this system.

Transient exposure of the luciferase reporter transgene to KRAB-PAX3-HBD induces stable silencing

A hallmark property of HP1-dependent gene silencing is that the silenced state is stably maintained through many cell divisions (Lu et al. 1998). To determine if there is a stable component to KRAB-KAP1-HP1-mediated gene silencing in the KPHBD21 cell line, we performed 4-OHT washout experiments. We took advantage of the fact that 4-OHT is readily removed from cells and that its effects on HBD fusion proteins are readily reversible (Littlewood et al. 1995; Pelengaris et al. 1999). A 24-h, 4 -OHT treatment produced $\sim 24$-fold reduction in lucif- erase activity (Fig. 7A; filled bars). Twenty-four hours after hormone removal, the luciferase activity was only two- to threefold lower than a duplicate dish, which had not been treated with 4-OHT, thus showing substantial reversal of the repressed state and verifying that the hormone was removed. However, dishes harvested at 2, 3, and $4 \mathrm{~d}$ after 4-OHT removal still maintained a substantially lower basal luciferase level than an untreated duplicate dish. The hormone had no effect on cell growth rate and the cells went through about four rounds of cell division during the 4 - $d$ time period. This result was even more pronounced when the initial 4-OHT treatment was for $48 \mathrm{~h}$ (Fig. 7A, patterned bars): Dishes maintained in the absence of hormone for $4 \mathrm{~d}$ showed approximately sixfold lower basal luciferase activity compared to untreated dishes. This result suggested that gene silencing might be stably maintained in a subpopulation of cells.

To further explore this phenomenon, we performed longer-term, 4-OHT treatment and washout studies (Fig. 7B). A 2-, 4-, or 6-d 4-OHT treatment of KPHBD21 cells strongly repressed the reporter luciferase activity $(>50$ fold reduction in luciferase activity at $6 \mathrm{~d}$ ). However, following 4-OHT removal, activity was substantially, but never completely, recovered. This effect was still evident at $8 \mathrm{~d}$ post-4-OHT removal, a time course that 
Ayyanathan et al.

A
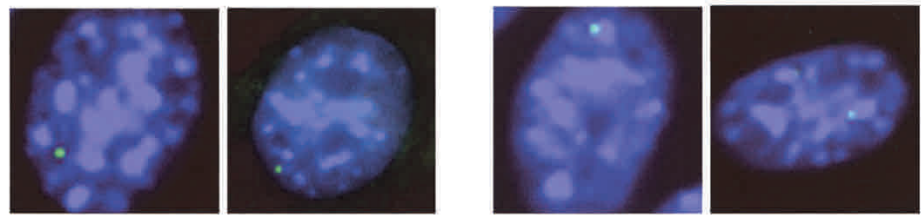

B
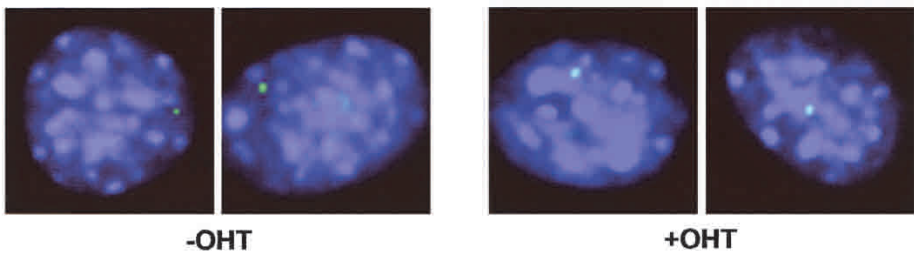

$-\mathrm{OHT}$

C

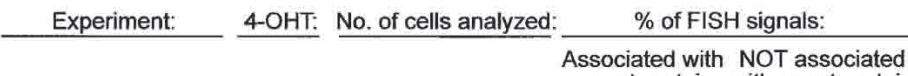
KPHBD21 cells were seeded onto glass coverslips and treated with either vehicle (-OHT) or 4-OHT (+OHT). FISH was carried out using luciferase probe and the nuclear DNA was visualized by staining with either DAPI $(A)$ or Hoechst $(B)$. The number of cells analyzed for each condition is indicated $(C)$. The results are presented as the percent of FISH signals that were either associated (whitish green dots) or not associated (green dots) with the DAPI- or Hoechst-stained spots. Associated with NOT associated
counter-stain with counter-stain

\begin{tabular}{|c|c|c|c|c|}
\hline & & & $\begin{array}{l}\text { Associated with } \\
\text { counter-stain }\end{array}$ & $\begin{array}{l}\text { NOT associated } \\
\text { with counter-stain }\end{array}$ \\
\hline $\begin{array}{l}\text { Luciferase-FISH with } \\
\text { DAPI counter-stain }\end{array}$ & - & 90 & 27 & 73 \\
\hline $\begin{array}{l}\text { Luciferase-FISH with } \\
\text { DAPI counter-stain }\end{array}$ & + & 156 & 69 & 31 \\
\hline $\begin{array}{l}\text { Luciferase-FISH with } \\
\text { Hoechst counter-stain }\end{array}$ & - & 82 & 29 & 71 \\
\hline $\begin{array}{l}\text { Luciferase-FISH with } \\
\text { Hoechst counter-stain }\end{array}$ & + & 188 & 72 & 28 \\
\hline
\end{tabular}

included extensive washing of each dish every day, and included a trypsinization and replating at semiconfluent cell densities. No repression was observed in two cell clones containing KRAB(DV)-PAX3-HBD fusion protein (Fig. 7C). Moreover, though substantial repression was observed in each of two SNAG-PAX3-HBD cell clones after a 4-d hormone treatment, the luciferase activity was fully recovered following 4-OHT removal (Fig. 7D).

\section{KRAB-KAP1-HP1 mediated gene silencing is mitotically heritable over many cell generations}

HP1-dependent gene variegation reflects the ability to maintain gene silencing over many cell generations in a clone of cells. To determine if a similar effect occurred at a euchromatic gene bound by HP1, we performed luciferase activities in cell populations that were transiently pulsed with 4-OHT. Three subclones of the KPHBD21 cell line, KPHBD21-08, KPHBD21-39, and KPHBD21-49, were further studied. Duplicate dishes of cells were treated with 4-OHT or vehicle for $4 \mathrm{~d}$, then washed, and subjected to a limiting dilution cloning. Clones were expanded in the absence of $4-\mathrm{OHT}$ for $\sim 40$ population doublings and tested for basal luciferase activity (Fig. 8A). For KPHBD21-08, 69 untreated subclones were isolated: their normalized luciferase activities showed a mean of $\sim 10^{5}$ light units/O.D. of protein and varied $<7$-fold from lowest to highest. However, subline KPHBD21-08 cells that had received 4-OHT prior to single cell cloning yielded a set of subclones with a dramatic skewing of activities. More than one-third of 65 clones yielded basal luciferase activities substantially lower than the lowest subclone derived from the untreated population (Fig. 8B).
Remarkably, a portion of the clones showed barely detectable luciferase activities.

A statistical analysis using Fisher's test (F-test), which compares the variances of two samples, yielded a highly significant $\mathrm{F}$ value of 0.00000003 . Identical results were obtained with subclones KPHBD21-39 and KPHBD2149 , where the F values comparing luciferase activity in untreated and treated populations were $\mathrm{F}=0.00074$ and $\mathrm{F}=0.00014$, respectively (Fig. $8 \mathrm{~B}$ ). The subclones maintain resistance to zeocin and G418 and thus have not deleted the transgenes. Moreover, the stably repressed clones have maintained the silent state for $>10$ mo in culture (data not shown). These results strongly suggest that transient recruitment of the KRAB-KAP1-HP1 complex to a euchromatic gene produces a silenced state that is mitotically heritable and does not require a persistent DNA-binding component.

\section{Molecular characteristics of the target locus in the silenced and expressed clones}

To understand the molecular basis for this stable silencing, we characterized the physical state of the silent and expressed luciferase genes. We selected silent (cl 39-40) and expressed (cl 39-45) subclones whose normalized luciferase activities were three orders of magnitude different (Fig. 9A, top panel). Using ChIP, we observed a strong enrichment of KAP1 (11.66-fold), SETDB1 (10.33-fold), HP1 $\alpha$ (6.93-fold), H3-MeK9 (5.3-fold), and a moderate enrichment of HP1 $\gamma(2.43$-fold) proteins in the silent clone compared to the expressed clone (Fig. 9A, bottom panel). However, the level of the KRAB-PAX3-HBD component at the transgene was very low and similar in the silent 


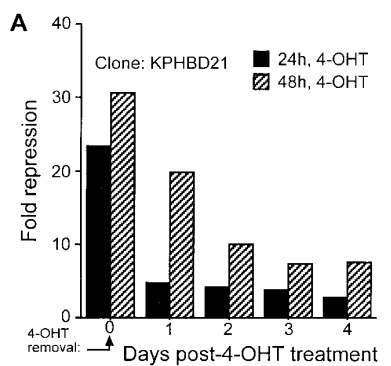

B
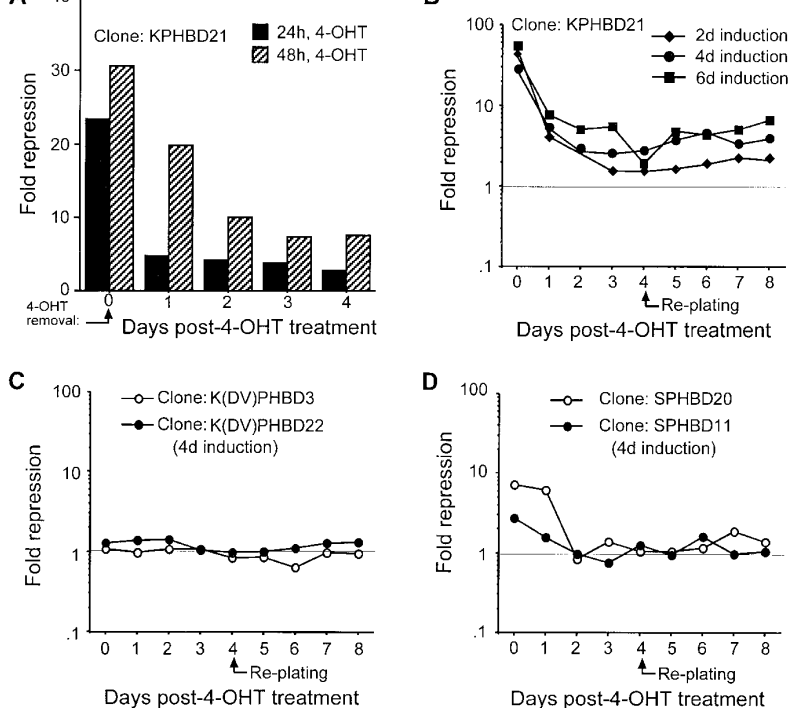

Figure 7. The KPHBD protein induces stable repression of the luciferase transgene. (A) Transient 4-OHT treatment of KPHBD21 cells induces a stable silencing component. Duplicate dishes of KPHBD21 cells were treated with either vehicle or 4-OHT $(+\mathrm{OHT})$ continuously for 24 or $48 \mathrm{~h}$ and washings performed. Pairs of dishes $(-/+\mathrm{OHT})$ were harvested at the indicated time points post 4-OHT removal and fold repression was determined. Filled bars, 24-h 4-OHT treatment; patterned bars, 48-h 4-OHT treatment. (B) A longer 4-OHT treatment of KPHBD21 cells can lead to a larger stable silencing component. Duplicate dishes of KPHBD21 cells were treated with either vehicle or 4-OHT continuously for 2,4 , or $6 \mathrm{~d}$. Washings and replatings were performed as described in Materials and Methods. Pairs of dishes $(-/+\mathrm{OHT})$ were harvested every day and fold repression was determined. $\bullet, 2 \mathrm{~d}$ of $4-\mathrm{OHT}$ treatment; $\bullet, 4 \mathrm{~d}$ of 4-OHT treatment; $\mathbf{\square}, 6 \mathrm{~d}$ of 4-OHT treatment. (C) 4-OHTinduced repression is not observed in $\mathrm{K}(\mathrm{DV}) \mathrm{PHBD}$ clones. The $\mathrm{K}(\mathrm{DV}) \mathrm{PHBD} 3(\mathrm{O})$ and $\mathrm{K}(\mathrm{DV}) \mathrm{PHBD} 22(\bullet)$ clonal cell lines were treated with vehicle or 4-OHT continuously for $4 \mathrm{~d}$, washed extensively, and fold repression determined. (D) 4-OHT-induced silencing component is not observed in SPHBD clones. The SPHBD11 (O) and SPHBD20 (O) clonal cell lines were treated with vehicle or 4-OHT continuously for $4 \mathrm{~d}$, washed extensively, and fold repression determined.

and active clones. To verify that the PAX3 DNA binding sites are present and accessible in the silent clone, we transfected a VP16-PAX3 plasmid that functions as a powerful activator. We observed a dose-dependent activation of the silent luciferase locus (Fig. 9B). These results suggest that the molecular components of the KRAB-KAP1-HP1 repression pathway are constitutively present at the silenced locus and also that the maintenance of the silent state is not the result of persistent DNA binding of the KRAB-PAX3-HBD protein.

To further characterize the silent clone, we treated the cells with 5-azacytidine (5AC) and trichostatin-A (TSA). Treatment with either 5AC or TSA alone did not significantly reactivate the locus (Fig. 9C). However, sequential treatment with 5AC followed by TSA was highly synergistic in reactivating the silent locus (Fig. 9C) suggesting that the silent state may be maintained as a result of DNA methylation (Cameron et al. 1999). To confirm this, we determined the methylation status of the TK promoter regions of the silent and active clones by methylation-specific PCR (MSPCR; Fig. 9D; Herman et al. 1996). The methylation-specific primer set (M) generated a strong amplification product using DNA from the silent clone. However, no product was seen using DNA from the active clone. Conversely, the unmethylated specific primers $(\mathrm{U})$ only produced a product from the active clone. These results suggest that the silent and active clones have different CpG methylation profiles at the promoter.

To map regions of methylation, we sequenced the cloned PCR products derived from bisulfite-treated genomic DNAs (Fig. 9E). The active clone showed nonrandom CpG methylation that was highly restricted to the region immediately surrounding the transcription start site. However, the silent clone showed dramatically en-

\section{A}
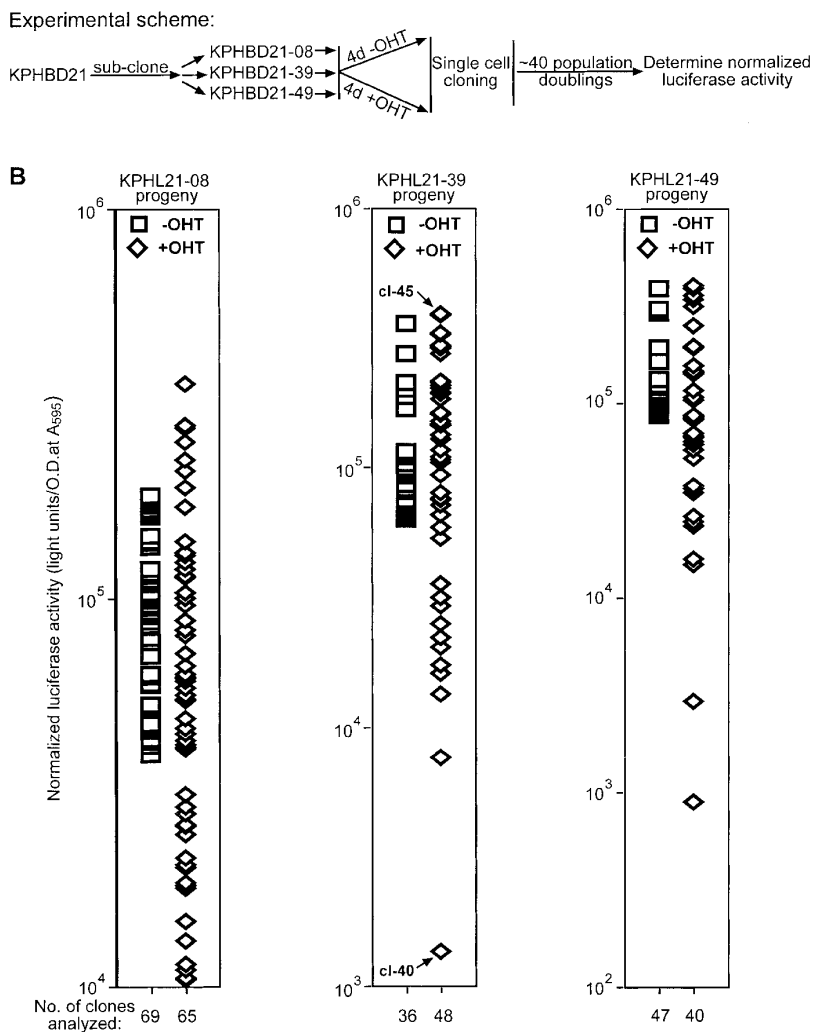

Figure 8. Clonal analysis of luciferase gene expression in KPHBD21 cells. (A) An experimental scheme designed to measure variegated expression of the luciferase gene in KPHBD21 cells. (B) Normalized luciferase activities for single cell progeny derived from KPHBD21-8, KPHBD21-39, or KPHBD21-49. Each $\square$ and $\diamond$ represents an independent single-cell subclone of the parental line treated with either vehicle $(-\mathrm{OHT})$ or 4-OHT $(+\mathrm{OHT})$, respectively. The total number of single-cell subclones analyzed for each parental line is indicated at the bottom. Arrows denote the silent ( $\mathrm{cl} \mathrm{39-40)}$ and active (cl 39-45) clones studied in detail. 
Ayyanathan et al.

Figure 9. Molecular characteristics of the active and silent clones. (A) Prior to ChIP experiments, the silent (cl 39-40) and active (cl 39-45) clones were tested for their basal luciferase activities (top panel). Next, the cross-linked chromatin fractions obtained from silent ( $\mathrm{cl} 39-40)$ and active (cl 39-45) clones were used in ChIPs with anti-PAX3, KAP1, SETDB1, HP1 $\alpha, \mathrm{HP} 1 \gamma$, and MeK9 antibodies. The input and the immunoprecipitated DNAs were amplified using TKP1 and LUC1 primers (Fig. 2A). Fold difference was determined by PhosphorImager analysis of the Southern blots (bottom panel). (B) Indicated concentrations of VPDBD plasmid was transiently transfected into the silent clone (cl 39-40), the cell lysates were assayed for luciferase activities and normalized with $\beta$-galactosidase values. The filled and patterned bars represent results obtained from two independent experiments. $(C)$ The silent (cl 39-40) and active ( $\mathrm{cl} 39-45)$ clones were plated in multiple dishes and treated with the indicated chemicals for specified durations. The filled and patterned bars represent the luciferase activity obtained from duplicate dishes. $(D)$ MSPCR. Genomic DNAs extracted from the silent (cl 39-40) and active (cl 39-45) clones were treated with sodium bisulfite and amplified using unmethylated sense (US) or methylated sense (MS) primers and an antisense primer (UMA1) belonging to the TK promoter indicated in $E$ and shown. $(E)$ Sodium bisulfite-genomic sequencing. The bisulfite-modified genomic DNAs of the silent (cl 39-40) and active (cl 39-45) clones were PCR-amplified using UMS1 (sense) and UMA1 (antisense) primers. The PCR products were TA-cloned into pCR II vector (Invitrogen). A representative selection of clones from both $\mathrm{cl}$ 39-40 and cl 39-45 were sequenced and the results presented. Hanging $\diamond$, the positions of CpG residues; $\square$, the unmethylated $\mathrm{CpG} ; \mathbf{\square}$, methylated $\mathrm{CpG}$ residues. Arrows pointing up mark the $\mathrm{CpG}$ residues that are preferentially methylated in the genomic clones of $\mathrm{cl} 39-40$.

hanced density of $\mathrm{CpG}$ methylation that was spread both $5^{\prime}$ and $3^{\prime}$ of the transcription start site. A total of 12 new $\mathrm{CpG}$ sites were methylated in the silenced clone (Fig. 9E). Together, these results suggest that DNA methylation may contribute to the mitotically heritable gene silencing we observe.

\section{Discussion}

Until recently, most of our insights into HP1 protein function and the role of heterochromatin in gene regulation have come from the study of position effect variegation (PEV) in Drosophila. Some of the key principles established include the following: pericentromeric and telomeric heterochromatin is enriched in DNA repeats that are packaged in a compact, chromatin structure.
A

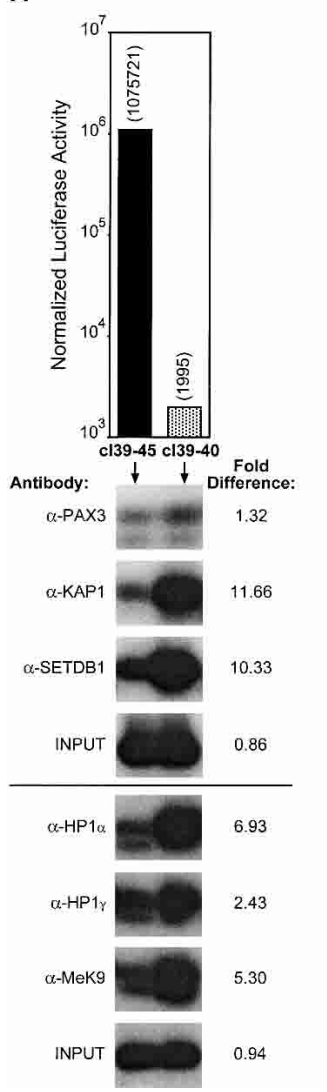

B

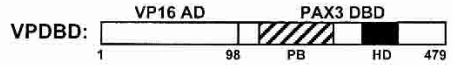

VPDBD (ug) cl $39-40$
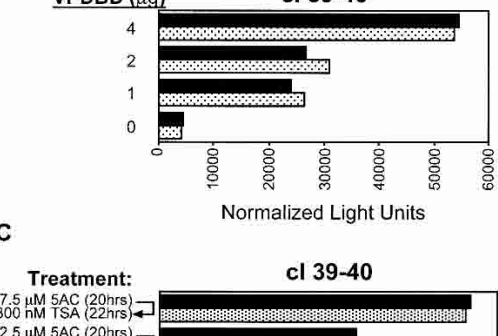
$\begin{aligned} 2.5 & \text { MM MAC } \\ 100 \mathrm{nM} \text { TSA (20hrs) } & 22 \mathrm{hrs}) \\ 3 & \end{aligned}$

$300 \mathrm{nM}$ TSA $(20 \mathrm{hrs})$
$7.5 \mu \mathrm{MM}$
$5 \mathrm{AC}(22 \mathrm{hrs})$

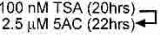

$7.5 \mu \mathrm{M} 5 \mathrm{AC}$ (22hrs) -

$2.5 \mu \mathrm{M} 5 \mathrm{AC}$ (22hrs) -

300 nM TSA (22hrs)

100 nM TSA (22hrs) -

$0.1 \%$ ethanol

$0.1 \%$ ethanot

Normalized Light Units

D

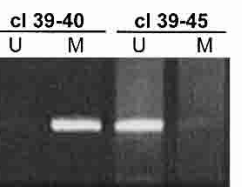

E
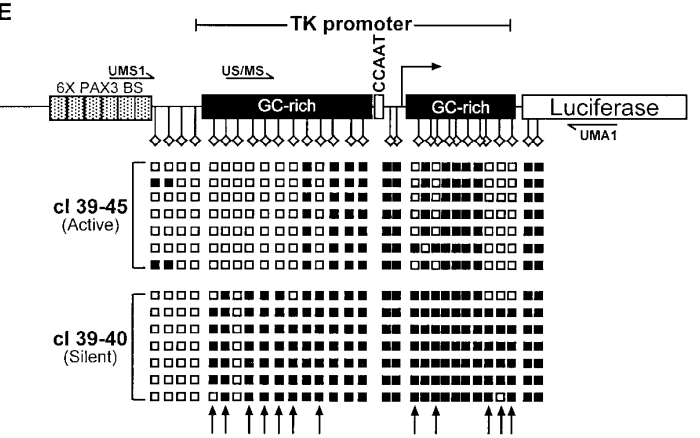

These regions have a low gene density, are late-replicating, and appear highly suppressed for both recombination and transcription (Wallrath 1998). The large blocks of constitutive heterochromatin are highly enriched in the HP1 protein, which can function as exquisite dosesensitive silencers of an adjacent euchromatic transgene. Once established, this silencing is mitotically heritable through many cell divisions giving rise to the classic variegated gene expression phenotype in the adult organs. Whether these principles will hold true in higher metazoans is a key question.

Recent evidence suggests a broader role for HP1 and heterochromatin in mammalian gene regulation. First, the human and mouse genomes contain at least three HP1 homologs, some of which display constitutive euchromatic localization (Ryan et al. 1999; Minc et al. 
2000). Second, heterodimerization can occur among these HP1 isoforms (Nielsen et al. 2001). Third, there are a host of regulatory proteins, which target HP1 to specific loci (Lechner et al. 2000; Smothers and Henikoff 2001). Finally, there is distinct tissue-, cell-type specificity of the HP1 isoforms including an emerging role in tumor progression (Kirschmann et al. 2000).

In this article, we have established some of the first principles for the mechanism of action of mammalian $\mathrm{HP} 1$ at a euchromatic locus. The KRAB-KAP1 repression system we used is a physiologically relevant targeting mechanism for HP1 proteins and, in addition, coordinates two other activities that are likely to be required for silencing: recruitment of the NuRD-HDAC complex (Schultz et al. 2001) and recruitment of the methyltransferase, SETDB1 (Schultz et al. 2002). Our results support the following conclusions: (1) The KRAB domain is able to coordinate machinery for strong transcriptional repression of an integrated, chromatinized RNA pol II transcribed target gene; (2) repression is relatively shortrange; (3) repression is accompanied by a highly localized chromatin compaction; (4) the KAP1 corepressor, and $\mathrm{HP} 1 \alpha / \gamma$ proteins are physically associated with the repressed gene in a highly localized manner; (5) the induced, silent state of the transgenic reporter is mitotically heritable in the absence of hormone for at least 40 population doublings; and (6), stable silencing is apparently specific for the KRAB-KAP1-HP1 mechanism as other repression domain fusions (which do not bind HP1) do not induce a heritable, silenced state. Together, these results strongly suggest that we have established a model for HP1-dependent silencing and variegation of a euchromatic gene in a mammalian cell line.

A critical issue for interpretation of these results is the chromatin environment of the integrated reporter transgene. We strongly favor the designation of the luciferase reporter as euchromatic based upon the following functional criteria: (1) All clones show a high basal level of luciferase activity; (2) all clones both express, and show physical linkage to the zeocin resistant cassette; (3) the reporter genes are packaged into a nuclease-accessible chromatin structure; and (4) interphase FISH shows the expressed reporter transgene present in euchromatic chromosome territories. Thus, while designation of a gene as euchromatic is historically based upon cytological analyses, clearly, the reporter plasmids have integrated into a region permissive for a high level of expression.

\section{The KRAB box functions as a short range repressor}

A clear result with this system is that the mechanism of KRAB-mediated repression appears to function over relatively short distances in chromatin. This property of a repression domain, that is, the ability to mediate longrange versus short-range repression has emerged as a key determinant of the biological function for a repressor protein (Gray and Levine 1996). KRAB-mediated, shortrange repression was accompanied by highly localized chromatin compaction and a physical association of the
KPHBD protein at the PAX3 DNA recognition sequences. The KAP1 and HP1 proteins were enriched at the TK promoter. Remarkably, the physical association of these proteins appears to only span a few nucleosomes because a region $\sim 1.2 \mathrm{kbp}$ away was devoid of cross-linkable protein. Such a short-range repressor property is also exhibited by the retinoblastoma $(\mathrm{Rb})$ repressor protein, which has been shown to remodel a single nucleosome at the promoter region (Morrison et al. 2002). In light of these results, it is remarkable that we also detect spatial relocalization of the gene in the interphase nucleus to a block of constitutive heterochromatin. Intuitively, one would think that such a long-range relocalization adjacent to a large block of A-T-rich condensed chromatin would have long-range silencing effects on the gene. While one caveat to this result is the potential presence of a cryptic insulator/boundary element between the luciferase and zeocin genes, we favor the notion that silencing mediated by a short-range repressor may occur by highly localized looping into heterochromatic environments (Seum et al. 2001).

\section{KRAB-KAP1-HP1-mediated gene silencing is mitotically heritable}

The most striking finding in this study is that transgene silencing is apparently mitotically heritable in cell culture. This is the hallmark property that distinguishes HP1-dependent PEV from other mechanisms of repression. Instead of physical linkage via translocation of the euchromatic gene to adjacent heterochromatin as occurs in PEV, we have relied on transient targeting of HP1 to a transcribed locus using the KRAB-KAP1 system. Our results suggest that a pulse of KRAB-KAP-HP1 protein induces a stable, silenced state that can be detected at high frequency in clonal subpopulations following growth of $>40$ cell generations in the absence of hormone. Because the biological effects of HBD fusion proteins are readily reversible following removal of hormone, we conclude that the stable silencing we observe is being maintained in the absence of the KPHBD DNA binding activity. This is further supported by the observation that SNAG domain-mediated repression (which does not involve HP1) is completely reversible by hormone withdrawal under the same experimental conditions.

A key observation is that silencing did not appear to spread along the template into the adjacent zeocin transcription unit. Spreading is commonly observed in pericentromeric heterochromatin-mediated PEV in Drosophila. Because we continually selected for zeocin expression (via drug selection) during growth of the singlecell clones after the 4-OHT-pulse, this selection pressure may have both impeded spreading and the establishment of a larger domain of silencing. Therefore, we repeated the clonal analysis in the absence of zeocin to determine if a higher frequency of stably silenced clones could be observed. However, the same frequency of stably silenced clones was observed in the absence of zeocin when compared to the +zeocin experiment (data not 
shown). We conclude that silencing of euchromatic genes via localized recruitment of HP1 may be unique to $\mathrm{KRAB}$ repressor domain and also that $\mathrm{KRAB}$ is fundamentally different from the other repressor domains in this property.

\section{HP1 mediated silencing of euchromatic genes}

Our study is one of the first to document the physical characteristics of a variegating euchromatic gene repressed by HP1 in a mammalian cell. Previously, a murine CD2 transgene reporter was shown to variegate in the thymus in response to HP1 dose (Festenstein et al. 1999). Interestingly, variegation could be either enhanced or repressed by HP1 dose, depending upon integration site (Festenstein et al. 1999). Recently, a set of apparently euchromatic Drosophila genes were identified that may be targets for dose-dependent HP1 regulation and can be affected by known modifiers of Drosophila PEV (Hwang et al. 2001). However, it is unclear if they variegate and/or what the nature of their chromatin structure is. A common theme among these and other studies of PEV is that variegation is extremely sensitive to HP1 dosage (Eissenberg et al. 1992; Hwang et al. 2001). It will be important to determine if this HP1 dose sensitivity holds true for repression of a mammalian euchromatic gene and if it can influence the stable component demonstrated in our system.

\section{The interplay between histone methylation and DNA methylation}

Our comparative ChIP analysis of silent and active clones clearly shows enrichment of KAP1, SETDB1, $\mathrm{HP} 1$, and $\mathrm{H} 3-\mathrm{MeK} 9$ at the silenced luciferase transgene promoter, all of which are likely to contribute to the stably silenced phenotype. However, most remarkable is the finding of increased DNA methylation in the stably silenced clone also centered on the proximal promoter region bound by these proteins. That this DNA methylation contributes to the silencing is suggested by the potent reactivation of the silent locus by the combined action of 5AC + TSA. This observation suggests that H3MeK9 methylation and HP1 recruitment on a euchromatic gene may ultimately lead to DNA methylation. Identifying which component of the histone-directed silencing machinery serves as the signal for recruitment and/or activation of the DNA methyltransferases required for carrying out the DNA modification will be critical for understanding this system. Moreover, once the DNA methylation mark is established, it likely plays an active role in maintaining the histone-directed machinery at the silent locus. This could be accomplished in two ways. First, the MBD2/3 component of the NuRD histone deacetylase complex could directly bind the methylated DNA and maintain HDAC activity at the locus. Second, in addition to the catalytic SET domain, the SETDB1 protein also encodes a CpG DNA methyl binding domain, which, if functional, would maintain the H3-MeK9 activity at the locus (Schultz et al. 2002). That this may occur is supported by our preliminary observation that $5 \mathrm{AC}+\mathrm{TSA}$ reactivation is accompanied by rapid loss of SETDB1 and H3-MeK9 at the locus as assessed by ChIP assays (K. Ayyanathan and F.J. Rauscher, unpubl.). In summary, the development of this tissue culture model will provide a valuable system to study in detail the sequence of events and the coordinated interplay between histone methylation, HP1 deposition, and DNA methylation.

\section{Materials and methods}

Expression and reporter plasmids

The construction of the pcKRAB-PAX3 (pcKP) plasmid has been described (Ayyanathan et al. 2000). The pcKRAB-PAX3-HBD (KPHBD) plasmid was constructed by fusing the estrogen receptor $\left(\mathrm{ERHBD}^{\mathrm{TM}}\right)$ in frame with the $\mathrm{COOH}$ terminus of the PAX3 DNA binding domain (DBD) at a unique EcoRI site. The pcKRAB(DV)-PAX3-HBD (K(DV)PHBD) plasmid was constructed by subcloning a mutant $\mathrm{KRAB}\left(\mathrm{DV}_{18,19} \mathrm{AA}\right)$ domain (Margolin et al. 1994) as a HindIII/BamHI fragment into pcKRAB-PAX3HBD plasmid, thus replacing the wild-type KRAB domain. A similar strategy was utilized to construct the pcSNAG-PAX3HBD (SPHBD), pcPLZF(POZ)-PAX3-HBD (PPHBD), pcEngrailedPAX3-HBD (EPHBD), and pcWT1-PAX3-HBD (WPHBD) expression plasmids. The pcVP16-PAX3 (VPDBD) expression plasmid was constructed by inserting the VP16 acidic activation domain (residues 1-98) using a similar approach. All PCR-derived nucleotide sequences and the appropriate fusion junctions were confirmed by sequencing both DNA strands. A PvuII fragment (zeocin ${ }^{\mathrm{R}}$ cassette) from pcDNA3.1/Zeo plasmid (Invitrogen) was cloned into a unique PvuII site in the CD19-TK-LUC plasmid to generate the CD19-TK-LUC-Zeo ${ }^{\mathrm{R}}$ plasmid (Ayyanathan et al. 2000).

\section{Antibodies}

The sources of antibodies are: $\alpha$-PAX3 IgG (Fredericks et al. 2000 ), affinity-purified $\alpha$-KAP1 (raised against amino acids 20418; Schultz et al. 2001), $\alpha$-SETDB1 (Schultz et al. 2002), $\alpha$-H3MeK9 (Abcam, Inc.; this antibody recognizes di-methyl Lys 9), $\alpha$-NT2 (raised against amino acids 323-345; Tanaka et al. 2002), and $\alpha-H P 1 \alpha$ and $\alpha-H P 1 \gamma$ IgGs. The $\alpha-H P 1 \alpha$ and $\alpha-H P 1 \gamma$ are mouse monoclonal antibodies, which were produced using 6-HIS-tagged, full-length human antigens. These reagents do not cross-react with the other human or mouse HP1 orthologs and will be described elsewhere (D.C. Schultz, M.S. Lechner, K. Ayyanathan, and F.J. Rauscher III, unpubl.).

\section{Transient transfections and luciferase reporter assays}

Protein expression was confirmed by transient transfection of COS-1 cells followed by immunoprecipitation of the $\left[{ }^{35} \mathrm{~S}\right]-\mathrm{L}$ methionine-labeled extracts with $\alpha$-PAX3 IgG (Ryan et al. 1999; Ayyanathan et al. 2000). 4-OHT-dependent repression potentials were monitored via transient transfection as previously described (Ayyanathan et al. 2000). Cells were treated with vehicle $(0.1 \%$ ethanol) or $500 \mathrm{nM} 4-\mathrm{OHT}$ (Research Biochemicals International). Fold repression was determined as the ratio of normalized light units in vehicle-treated cells versus 4-OHT treated cells.

For 4-OHT washout experiments, cells were seeded at $0.5 \times 10^{4}$ in $60-\mathrm{mm}$ dishes. Duplicate dishes of cells were then 
treated with either $500 \mathrm{nM} 4-\mathrm{OHT}(+\mathrm{OHT})$ or $0.1 \%$ ethanol $(-\mathrm{OHT})$ for the indicated time. At the end of induction, one dish of -OHT and +OHT-treated cells were harvested while the remaining dishes were subjected to three washes each day. On fourth day, the cells were harvested by trypsinization and replated into new dishes. Washings were continued for an additional $4 \mathrm{~d}$. Cells were harvested daily and normalized luciferase activities determined.

Generation and characterization of stably transfected cell clones

NIH3T3 cell lines containing a stably expressed chimeric repressor and the CD19-TK-LUC-Zeo ${ }^{\mathrm{R}}$ reporter plasmid were generated by cotransfection and selection in growth medium containing $500 \mu \mathrm{g} / \mathrm{mL} \mathrm{G418}+100 \mu \mathrm{g} / \mathrm{mL}$ zeocin. Colonies were ring-cloned, expanded, and tested for luciferase activity. The luciferase activities were normalized to protein concentration and expressed as light units/O.D. at $\mathrm{A}_{595}$. Stable expression of the chimeric RD-PAX3-HBD proteins in clones was tested by immunoprecipitation with $\alpha-\mathrm{PAX} 3$.

\section{Quantitative RT-PCR (Q-RT-PCR)}

Total RNAs were isolated using TRIzol Reagent (Life Technologies) and oligo-dT primed first-strand cDNAs produced. Luciferase, neomycin ${ }^{\mathrm{R}}$, zeocin ${ }^{\mathrm{R}}, \mathrm{NT} 2$, Col11a2, and RXR $\beta$ mRNAs were amplified by PCR for the number of cycles indicated. The respective primer pairs were: LUC2 (5'-CAAGGATAT GGGCTCAC-3') and LUC3 (5'-GACCTTTCGGTACTTCG$\left.3^{\prime}\right)$, NEO1 (5'-TCAGCGCAGGGGCGCCCGGTTCTTT-3') and NEO2 (5'-ATCGACAAGACCGGCTTCCATCCGA-3'), ZEO1 (5'-ATGGCCAAGTTGACCAG-3') and ZEO2 (5'-TCAGTCC TGCTCCTCG-3'), NT2-1 (5'-GCCAGGCTAGAAGGGAGG$\left.3^{\prime}\right)$ and NT2-2 (5'-GGTGTCTGTTGAGGTTGG-3'), COL1 (5'GGCCTCAGCCTAGCAGATGG-3') and COL2 (5'-GGCTTA TGAAGTCTTGCTGG-3'), RXR1 (5'-GGCTCTGTGCAATC TGCGGG-3') and RXR2 (5'-GTCCACAGGCATCTCCTCAG GG-3'). Following electrophoresis and Southern blotting, the images were quantified using ImageQuant (Molecular Dynamics).

\section{In vivo analysis of chromatin structure}

Nuclei were prepared essentially as described (Mymryk et al. 1997). For the restriction enzyme accessibility assays, the nuclei were diluted into appropriate $1 \times$ restriction enzyme buffers in a $500-\mu \mathrm{L}$ reaction volume and digested with 250 units of the indicated enzymes for $10 \mathrm{~min}$ at room temperature. The reaction was terminated by adding $100 \mu \mathrm{g}$ of proteinase- $\mathrm{K}$ in $10 \mathrm{mM}$ Tris- $\mathrm{HCl}$ at $\mathrm{pH}$ 8.0, $10 \mathrm{mM}$ EDTA, $10 \mathrm{mM} \mathrm{NaCl}$, and incubated at $37^{\circ} \mathrm{C}$ for $14-16 \mathrm{~h}$. These samples were phenol:chloroform extracted and ethanol precipitated. The purified DNA was digested with BamHI to completion and purified. Equal amounts of the DNA samples were taken for reiterative, primer extension PCR reactions with the following ${ }^{32} \mathrm{P}$-labeled primers: LUC1 ( $5^{\prime}$-TCCAGGAACCAGGGCGTATCTCT-3') or ZEO2 or NEO2. Primer extension products were extracted with phenol:chloroform and ethanol precipitated. Dried DNA pellets were dissolved in formamide gel-loading buffer and electrophoresed in $7 \mathrm{M}$ Urea $/ 5 \%$ acrylamide gels in TBE buffer. The gels were fixed in $10 \%$ acetic acid, dried, and autoradiographed.

\section{ChIP}

Soluble, sonicated chromatin was prepared essentially as described (Schultz et al. 2002). Chromatin fractions were immu- noprecipitated with $10 \mu \mathrm{g}$ of indicated antibodies and the immune complexes were recovered using protein-A sepharose beads and processed as described (Schultz et al. 2002). The immunoprecipitated and input DNA samples were used in quantitative PCR using the following oligonucleotides: LUC1, LUC2, LUC3, ZEO2, PBS3 (5'-GAATACACGGAATTGGA TCCG-3'), PBS1 (5'-GATCGATAATTCGAGCTACTG-3'), PBS2 (5'-GAGCTCGGTACCCGGGTCG-3'), TKP1 (5'-GCGC GGTCCCAGGTCCACTT-3'), SVP1 (5'-CCAGTTCCGCCCA TTCTCCC-3'), C1 (5'-GGATGCTGCCACGGCCTGAGG-3'), C2 (5'-GGGTCTGCCAGGAGCCTGTGG-3'), C3 (5'-GGGTC GCTATCTATAGCTGG-3'), C4 (5'-GTCCTTTCACACCAC GGCAG-3'), C5 (5'-GGCCTCAGCCTAGCAGATGG-3'), C6 (5'GAGCACTCAGACCTTCCAGAGG-3'), C7 (5' -GGAACATCA GGTGGTGACGG-3'), C8 (5'-GCAGCCCATCCTTCCCTGC AGG-3'). The PCR products were resolved on $1.5 \%$ agarose gels and the bands were quantified using IQMac v1.2 software.

\section{FISH}

For detection of the luciferase gene, either $0.1 \%$ ethanol (-OHT) or $500 \mathrm{nM} 4-\mathrm{OHT}(+\mathrm{OHT})$ treated KPHBD21 cells were fixed in $4 \%$ paraformaldehyde, permeabilized in $0.2 \%$ Triton X-100, and then treated with RNase. After equilibration in $2 \times$ SSC, cells were dehydrated in an ethanol series $(70 \%, 80 \%$, and $100 \%)$. The CD19-TK-LUC plasmid was labeled with biotin-16-dUTP by nick-translation and dissolved at $10 \mathrm{ng} / \mu \mathrm{L}$ in $50 \%$ formamide in $2 \times$ SSC containing $10 \%$ dextran sulfate, $100 \mathrm{ng} / \mu \mathrm{L}$ salmon sperm DNA, $1 \mu \mathrm{g} / \mu \mathrm{L}$ yeast tRNA, and $1.5 \mu \mathrm{g} / \mu \mathrm{L}$ Cot- 1 DNA. Both the probe and the cells were simultaneously heated at $91^{\circ} \mathrm{C}$ for $4 \mathrm{~min}$ to denature DNA and incubated overnight at $37^{\circ} \mathrm{C}$. After hybridization, specimens were serially washed at $37^{\circ} \mathrm{C}$ with $50 \%$ formamide in $2 \times$ SSC, $2 \times$ SSC, and $0.25 \times$ SSC. Hybridized probes were detected with FITC-streptavidin (Vector Laboratories). Finally, cells were equilibrated in PBS, stained for DNA with either DAPI or Hoechst $(2 \mathrm{ng} / \mathrm{mL})$ and mounted in Fluoromount G (Southern Biotechnology Associates, Inc). Cells were analyzed with a Leitz Fluovert inverted microscope equipped with a digital camera. Images were obtained using QED Imaging software.

\section{Clonal analysis of luciferase gene expression}

Three independent subclones (KPHBD21-8, KPHBD21-39, and KPHBD21-49) that express high-level luciferase activities were treated with either $500 \mathrm{nM} 4-\mathrm{OHT}(+\mathrm{OHT})$ or $0.1 \%$ ethanol (-OHT) for $4 \mathrm{~d}$ continuously and subjected to limiting dilution cloning in 96-well plates. Wells containing single cells were identified and the cells were propagated for $\sim 40$ doublings in normal growth medium. Whole-cell lysates were prepared from these individual progeny and normalized luciferase activities were determined.

\section{DNA methylation analysis}

MSPCR: Genomic DNAs were extracted from the silent (cl 39$40)$ and active (cl 39-45) clones, and $1 \mu \mathrm{g}$ of each was treated with sodium bisulfite to convert the unmethylated cytosines to uracil as described (Herman et al. 1996). These DNAs were PCR amplified using unmethylated sense (US; 5'-GTTGATTTGGG TATTGAGTTTGAG-3') or methylated sense (MS; 5'-GTCGA TTCGGGTATCGAGTTCG-3') primers (present in the TK promoter) and an antisense primer (UMA1; 5'-GGTTTTATTTTT TAGAGGATAGAATGG-3'; present near the start of luciferase cDNA). The PCR products were electrophoresed on a $1.5 \%$ agarose gel and photographed. 
Sodium bisulfite-genomic sequencing: The sodium bisulfitemodified DNAs were PCR amplified using UMS1 (sense; 5'GTTTTAGTGTTTTATGTTTTAGG-3') and UMA1 (antisense) primers that were present in regions free of any $\mathrm{CpG}$ residues (to avoid any preferential amplification). The PCR products were TA-cloned into the pCR II vector. At least 18 recombinant clones of each were sequenced in both directions. Results are presented for seven representative clones in each category.

\section{Acknowledgments}

We thank William Fredericks for proofreading the manuscript. We thank Trevor Littlewood and Gerard Evan for the ERHBD ${ }^{\mathrm{TM}}$ plasmid. We thank Nick Barlev and Shelley Berger for the ChIP protocol. We thank Jim Herman for advice on MSPCR and Bisulfite-genomic sequencing. We thank Andrey Loboda and Michael Showe for statistical analysis. K.A. is supported by CA095620. D.C.S. is supported by DAMD17-98-1-8269. M.S.L. is supported by CA09171. G.G.M. is supported by AI41136, AI52742, AI53237, and GM64691. F.J.R. is supported in part by National Institutes of Health grants, Core grant CA10815, CA92088, CA095561, DAMD17-96-1-6141, DAMD17-02-10631, the Irving A. Hansen Memorial Foundation, the Susan G. Komen Breast Cancer Foundation, and the Emerald Foundation. Support from Commonwealth Universal Research Enhancement Program, Pennsylvania Department of Health, is gratefully acknowledged.

The publication costs of this article were defrayed in part by payment of page charges. This article must therefore be hereby marked "advertisement" in accordance with 18 USC section 1734 solely to indicate this fact.

\section{References}

Abrink, M., Ortiz, J.A., Mark, C., Sanchez, C., Looman, C., Hellman, L., Chambon, P., and Losson, R. 2001. Conserved interaction between distinct Kruppel-associated box domains and the transcriptional intermediary factor 1 beta. Proc. Nat1. Acad. Sci. 98: 1422-1426.

Ayyanathan, K., Fredericks, W.J., Berking, C., Herlyn, M., Balakrishnan, C., Gunther, E., and Rauscher III, F.J. 2000. Hormone-dependent tumor regression in vivo by an inducible transcriptional repressor directed at the PAX3-FKHR oncogene. Cancer Res. 60: 5803-5814.

Baker, W.K. 1968. Position-effect variegation. Adv. Genet. 14: 133-169.

Bannister, A.J., Zegerman, P., Partridge, J.F., Miska, E.A., Thomas, J.O., Allshire, R.C., and Kouzarides, T. 2001. Selective recognition of methylated lysine 9 on histone $\mathrm{H} 3$ by the HP1 chromo domain. Nature 410: 120-124.

Cameron, E.E., Bachman, K.E., Myohanen, S., Herman, J.G., and Baylin, S.B. 1999. Synergy of demethylation and histone deacetylase inhibition in the re- expression of genes silenced in cancer. Nat. Genet. 21: 103-107.

Eissenberg, J.C., Morris, G.D., Reuter, G., and Hartnett, T. 1992. The heterochromatin-associated protein HP-1 is an essential protein in Drosophila with dosage-dependent effects on position-effect variegation. Genetics 131: 345-352.

Festenstein, R., Sharghi-Namini, S., Fox, M., Roderick, K., Tolaini, M., Norton, T., Saveliev, A., Kioussis, D., and Singh, P. 1999. Heterochromatin protein 1 modifies mammalian PEV in a dose- and chromosomal-context-dependent manner. Nat. Genet. 23: 457-461.
Fredericks, W.J., Ayyanathan, K., Herlyn, M., Friedman, J.R., and Rauscher III, F.J. 2000. An engineered PAX3-KRAB transcriptional repressor inhibits the malignant phenotype of alveolar rhabdomyosarcoma cells harboring the endogenous PAX3-FKHR oncogene. Mol. Cell. Biol. 20: 5019-5031.

Friedman, J.R., Fredericks, W.J., Jensen, D.E., Speicher, D.W., Huang, X.P., Neilson, E.G., and Rauscher III, F.J. 1996. KAP1 , a novel corepressor for the highly conserved KRAB repression domain. Genes \& Dev. 10: 2067-2078.

Gray, S. and Levine, M. 1996. Short-range transcriptional repressors mediate both quenching and direct repression within complex loci in Drosophila. Genes \& Dev. 10: 700710.

Herman, J.G., Graff, J.R., Myohanen, S., Nelkin, B.D., and Baylin, S.B. 1996. Methylation-specific PCR: A novel PCR assay for methylation status of CpG islands. Proc. Nat1. Acad. Sci. 93: 9821-9826.

Hwang, K.K., Eissenberg, J.C., and Worman, H.J. 2001. Transcriptional repression of euchromatic genes by Drosophila heterochromatin protein 1 and histone modifiers. Proc. Nat1. Acad. Sci. 98: 11423-11427.

James, T.C. and Elgin, S.C. 1986. Identification of a nonhistone chromosomal protein associated with heterochromatin in Drosophila melanogaster and its gene. Mol. Cell. Biol. 6: 3862-3872.

Jaynes, J.B. and O'Farrell, P.H. 1991. Active repression of transcription by the engrailed homeodomain protein. EMBO $\mathrm{T}$. 10: 1427-1433.

Jenuwein, T. and Allis, C.D. 2001. Translating the histone code. Science 293: 1074-1080.

Kirschmann, D.A., Lininger, R.A., Gardner, L.M., Seftor, E.A., Odero, V.A., Ainsztein, A.M., Earnshaw, W.C., Wallrath, L.L., and Hendrix, M.J. 2000. Down-regulation of HP1Hs $\alpha$ expression is associated with the metastatic phenotype in breast cancer. Cancer Res. 60: 3359-3363.

Kuo, M.H. and Allis, C.D. 1998. Roles of histone acetyltransferases and deacetylases in gene regulation. Bioessays 20: 615-626.

Lachner, M., O'Carroll, D., Rea, S., Mechtler, K., and Jenuwein, T. 2001. Methylation of histone H3 lysine 9 creates a binding site for HP1 proteins. Nature 410: 116-120.

Lechner, M.S., Begg, G.E., Speicher, D.W., and Rauscher III, F.J. 2000. Molecular determinants for targeting heterochromatin protein 1-mediated gene silencing: Direct chromoshadow domain-KAP-1 corepressor interaction is essential. Mol. Cell. Biol. 20: 6449-6465.

Li, X., Lopez-Guisa, J.M., Ninan, N., Weiner, E.J., Rauscher III, F.J., and Marmorstein, R. 1997. Overexpression, purification, characterization, and crystallization of the BTB/POZ domain from the PLZF oncoprotein. J. Biol. Chem. 272: 27324 27329.

Littlewood, T.D., Hancock, D.C., Danielian, P.S., Parker, M.G., and Evan, G.I. 1995. A modified oestrogen receptor ligandbinding domain as an improved switch for the regulation of heterologous proteins. Nucleic Acids Res. 23: 1686-1690.

Locke, J., Kotarski, M.A., and Tartof, K.D. 1988. Dosage-dependent modifiers of position effect variegation in Drosophila and a mass action model that explains their effect. Genetics 120: 181-198.

Lu, B.Y., Ma, J., and Eissenberg, J.C. 1998. Developmental regulation of heterochromatin-mediated gene silencing in Drosophila. Development 125: 2223-2234.

Madden, S.L., Cook, D.M., Morris, J.F., Gashler, A., Sukhatme, V.P., and Rauscher III, F.J. 1991. Transcriptional repression mediated by the WT1 Wilms tumor gene product. Science 253: $1550-1553$. 
Margolin, J.F., Friedman, J.R., Meyer, W.K., Vissing, H., Thiesen, H.J., and Rauscher III, F.J. 1994. Kruppel-associated boxes are potent transcriptional repression domains. Proc. Nat1. Acad. Sci. 91: 4509-4513.

Minc, E., Courvalin, J.C., and Buendia, B. 2000. HP1gamma associates with euchromatin and heterochromatin in mammalian nuclei and chromosomes. Cytogenet. Cell. Genet. 90: 279-284.

Morrison, A.J., Sardet, C., and Herrera, R.E. 2002. Retinoblastoma protein transcriptional repression through histone deacetylation of a single nucleosome. Mol. Cell. Biol. 22: 856-865.

Mymryk, J.S., Fryer, C.J., Jung, L.A., and Archer, T.K. 1997. Analysis of chromatin structure in vivo. Methods 12: 105114.

Nakayama, J., Rice, J.C., Strahl, B.D., Allis, C.D., and Grewal, S.I. 2001. Role of histone H3 lysine 9 methylation in epigenetic control of heterochromatin assembly. Science 292: $110-113$.

Nielsen, A.L., Oulad-Abdelghani, M., Ortiz, J.A., Remboutsika, E., Chambon, P., and Losson, R. 2001. Heterochromatin formation in mammalian cells: Interaction between histones and HP1 proteins. Mol. Cell 7: 729-739.

Pelengaris, S., Littlewood, T., Khan, M., Elia, G., and Evan, G. 1999. Reversible activation of c-Myc in skin: Induction of a complex neoplastic phenotype by a single oncogenic lesion. Mol. Cell 3: 565-577.

Peng, H., Begg, G.E., Schultz, D.C., Friedman, J.R., Jensen, D.E., Speicher, D.W., and Rauscher III, F.J. 2000. Reconstitution of the KRAB-KAP-1 repressor complex: A model system for defining the molecular anatomy of RING-B box-coiled-coil domain-mediated protein-protein interactions. J. Mol. Biol. 295: 1139-1162.

Rea, S., Eisenhaber, F., O'Carroll, D., Strahl, B.D., Sun, Z.W., Schmid, M., Opravil, S., Mechtler, K., Ponting, C.P., Allis, C.D., et al. 2000. Regulation of chromatin structure by sitespecific histone H3 methyltransferases. Nature 406: 593599.

Ryan, R.F., Schultz, D.C., Ayyanathan, K., Singh, P.B., Friedman, J.R., Fredericks, W.J., and Rauscher III, F.J. 1999. KAP-1 corepressor protein interacts and colocalizes with heterochromatic and euchromatic HP1 proteins: A potential role for Kruppel-associated box-zinc finger proteins in heterochromatin-mediated gene silencing. Mol. Cell. Biol. 19: 4366-4378.

Schultz, D.C., Friedman, J.R., and Rauscher III, F.J. 2001. Targeting histone deacetylase complexes via KRAB-zinc finger proteins: The PHD and bromodomains of KAP-1 form a cooperative unit that recruits a novel isoform of the Mi-2alpha subunit of NuRD. Genes \& Dev. 15: 428-443.

Schultz, D.C., Ayyanathan, K., Negorev, D., Maul, G.G., and Rauscher III, F.J. 2002. SETDB1: A novel KAP-1-associated histone $\mathrm{H} 3$, lysine 9-specific methyltransferase that contributes to HP1-mediated silencing of euchromatic genes by KRAB zinc-finger proteins. Genes \& Dev. 16: 919-932.

Seum, C., Delattre, M., Spierer, A., and Spierer, P. 2001. Ectopic HP1 promotes chromosome loops and variegated silencing in Drosophila. EMBO J. 20: 812-818.

Smothers, J.F. and Henikoff, S. 2001. The hinge and chromo shadow domain impart distinct targeting of HP1-like proteins. Mol. Cell. Biol. 21: 2555-2569.

Tanaka, K., Tsumaki, N., Kozak, C.A., Matsumoto, Y., Nakatani, F., Iwamoto, Y., and Yamada, Y. 2002. A Kruppel-associated box-zinc finger protein, NT2, represses cell-type-specific promoter activity of the $\alpha 2$ (XI) collagen gene. Mol. Cell. Biol. 22: 4256-4267.
Wakimoto, B.T. 1998. Beyond the nucleosome: Epigenetic aspects of position-effect variegation in Drosophila. Cell 93: 321-324.

Wallrath, L.L. 1998. Unfolding the mysteries of heterochromatin. Curr. Opin. Genet. Dev. 8: 147-153.

Wolffe, A.P. and Hansen, J.C. 2001. Nuclear visions: functional flexibility from structural instability. Cell 104: 631-634.

Wu, J. and Grunstein, M. 2000. 25 years after the nucleosome model: Chromatin modifications. Trends Biochem Sci. 25: 619-623.

Zhang, Y. and Reinberg, D. 2001. Transcription regulation by histone methylation: Interplay between different covalent modifications of the core histone tails. Genes \& Dev. 15: 2343-2360.

Zweidler-Mckay, P.A., Grimes, H.L., Flubacher, M.M., and Tsichlis, P.N. 1996. Gfi-1 encodes a nuclear zinc finger protein that binds DNA and functions as a transcriptional repressor. Mol. Cell. Biol. 16: 4024-4034. 


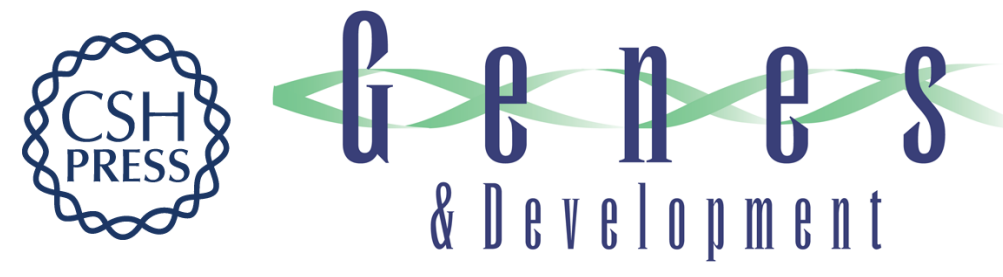

\section{Regulated recruitment of HP1 to a euchromatic gene induces mitotically heritable, epigenetic gene silencing: a mammalian cell culture model of gene variegation}

Kasirajan Ayyanathan, Mark S. Lechner, Peter Bell, et al.

Genes Dev. 2003, 17:

Access the most recent version at doi:10.1101/gad.1102803

$\begin{array}{ll}\text { References } & \begin{array}{l}\text { This article cites } 45 \text { articles, } 26 \text { of which can be accessed free at: } \\ \text { http://genesdev.cshlp.org/content/17/15/1855.full.html\#ref-list-1 }\end{array}\end{array}$

License

Email Alerting Receive free email alerts when new articles cite this article - sign up in the box at the top Service right corner of the article or click here.

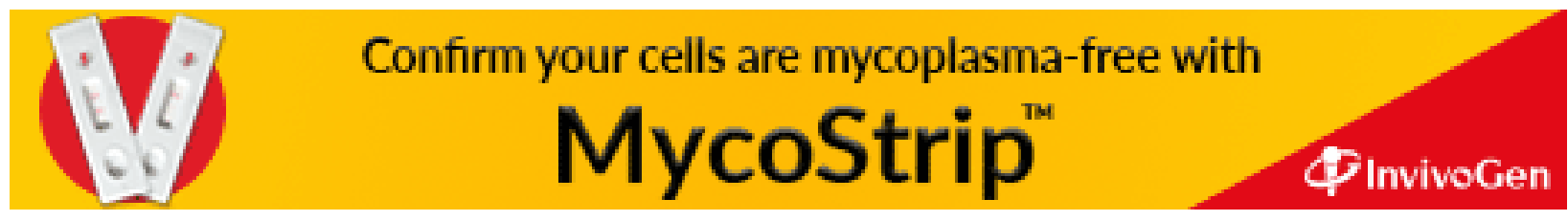

